\title{
Electron density profiles in the quiet lower ionosphere based on the results of modeling and experimental data
}

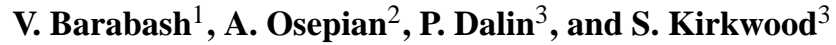 \\ ${ }^{1}$ Luleå University of Technology, Rymdcampus 1, 98192 Kiruna, Sweden \\ ${ }^{2}$ Polar Geophysical Institute, Halturina 15, 183023 Murmansk, Russia \\ ${ }^{3}$ Swedish Institute of Space Physics, Rymdcampus 1, 98192 Kiruna, Sweden \\ Correspondence to: V. Barabash (victoria.barabash@ltu.se) \\ Received: 23 August 2011 - Revised: 16 August 2012 - Accepted: 16 August 2012 - Published: 13 September 2012
}

\begin{abstract}
The theoretical PGI (Polar Geophysical Institute) model for the quiet lower ionosphere has been applied for computing the ionization rate and electron density profiles in the summer and winter D-region at solar zenith angles less than $80^{\circ}$ and larger than $99^{\circ}$ under steady state conditions. In order to minimize possible errors in estimation of ionization rates provided by solar electromagnetic radiation and to obtain the most exact values of electron density, each wavelength range of the solar spectrum has been divided into several intervals and the relations between the solar radiation intensity at these wavelengths and the solar activity index $F_{10.7}$ have been incorporated into the model. Influence of minor neutral species $\left(\mathrm{NO}, \mathrm{H}_{2} \mathrm{O}, \mathrm{O}, \mathrm{O}_{3}\right.$ ) concentrations on the electron number density at different altitudes of the sunlit quiet D-region has been examined. The results demonstrate that at altitudes above $70 \mathrm{~km}$, the modeled electron density is most sensitive to variations of nitric oxide concentration. Changes of water vapor concentration in the whole altitude range of the mesosphere influence the electron density only in the narrow height interval $73-85 \mathrm{~km}$. The effect of the change of atomic oxygen and ozone concentration is the least significant and takes place only below $70 \mathrm{~km}$.

Model responses to changes of the solar zenith angle, solar activity (low-high) and season (summer-winter) have been considered. Modeled electron density profiles have been evaluated by comparison with experimental profiles available from the rocket measurements for the same conditions. It is demonstrated that the theoretical model for the quiet lower ionosphere is quite effective in describing variations in ionization rate, electron number density and effective recombination coefficient as functions of solar zenith angle, solar activity and season. The model may be used for solving inverse
\end{abstract}

tasks, in particular, for estimations of nitric oxide concentration in the mesosphere.

Keywords. Ionosphere (Ion chemistry and composition; Ionization mechanisms; Modeling and forecasting)

\section{Introduction}

Characteristic features of the ion structure of the D-region between $50-90 \mathrm{~km}$ heights are the presence of ion clusters, formation of simple and complex negative ions, interactions between primary ions and chemically active minor neutral components. Knowledge of the ionospheric structure, in particular the height distribution of the electron number density as a function of geographical location, season and time is important for radio wave propagation. From a scientific point of view, investigation of the lower ionosphere and examination of its structure allow the study of coupling processes between the neutral atmosphere and the ionospheric plasma, and between space weather and Earth's geospace.

Despite of development and improvement of radiophysical methods for measurements of the electron number density, including ground-based techniques and sounding rockets, there is a large uncertainty in the obtained results. Moreover, during quiet conditions and weak auroral events, experimental data on electron density at altitudes below $80 \mathrm{~km}$ are often absent. Incoherent scattering of radio waves gives reliable information about the height distribution of the electron number density during quiet periods at altitudes above $75-80 \mathrm{~km}$. The partial reflection method allows reliable electron number density to be obtained in the quiet ionosphere only at altitudes above $80 \mathrm{~km}$. Rocket 
measurements that apply the Faraday rotation method give the most reliable data, but do not provide long-term data sets. In order to improve methods for prediction of radio wave propagation and to ensure communication, better knowledge of the spatial and temporal distribution of the electron density under various conditions is needed, i.e. in geomagnetic quiet and disturbed situations, for different seasons and solar zenith angles. There are several empirical and semi-empirical models of the D-region (for example, Friedrich and Torkar, 1992, 1998, 2001; Danilov, 2000; McKinnell and Friedrich, 2007) that have been proposed as inputs to the International Reference Ionosphere model (IRI). However, these models have not been applied for description of the great variability in the electron number density below $75-80 \mathrm{~km}$ nor under specific geophysical situations. This is especially important for stable operation, navigation and communications in very low and low frequency (VLF/LF) ranges, since these waves are reflected from the lower border of the D-region.

Theoretical models are useful tools for examining the structure of the lower ionosphere during various geophysical situations and at any heights if they take into account all basic processes and factors that influence the ionization balance. The principal purpose and the complexity of theoretical model construction is the correct description of the physical and chemical processes that create and support the ionosphere in the D-region. These processes are ionization and different types of chemical and recombination reactions. Efficiencies of ion-molecular reactions which, together with processes of ionization and recombination, form ionosphere structures depend on the local concentrations of long-lived species such as $\mathrm{NO}, \mathrm{H}_{2} \mathrm{O}, \mathrm{O}$ and $\mathrm{O}_{3}$. They, in turn, depend on solar illumination, season, ionization sources, solar activity, turbulence, diffusion, transport and other factors. Therefore, it is important to incorporate, into any model, realistic height profiles of the minor constituents that are appropriate for a given geophysical situations. However, for the present there is a lack of accurate experimental information on the height distribution of many of these constituents. Measurements demonstrate a significant difference in minor species concentrations at the altitudes of the mesosphere for similar geophysical conditions. Theoretical estimations of numerical density of minor species, obtained with different diffusivephotochemical models, but for the same conditions, also differ from each other and are not in good correlation with the experimental data. This creates a problem for suitable choice of minor constituents profiles in each concrete case and can lead to inaccuracies in the modeling of electron density and other ionospheric parameters.

The ion-chemical model developed by Smirnova et al. (1988) for the lower ionosphere has been used by Osepian et al. $(2008,2009 a, b)$ to investigate the influence of the atomic oxygen and ozone concentrations on the electron density and the ion composition at different altitudes in the D-region during solar proton events, when there are favorable conditions for accurate measurements of electron den- sity in the whole D-region, including the lower altitudes. The total PGI (Polar Geophysical Institute) model of ionizationrecombination cycle for the D-region takes into account sources of ionization, ion-molecular reactions that form positive cluster ions and complex negative ions from the primary ions, their dependence on temperature and number densities of minor neutral constituents, electron attachment to neutrals, electron photo-detachment of negative ions, photodissociation of negative ions, recombination of positive ions with electrons, reactions of ion-ion recombination. A computer algorithm for computation of ionization rates produced by solar protons has been developed and tested by Kirkwood (1988) and Kirkwood and Osepian (1995). Reliable measurements of solar proton fluxes in several energy intervals (by the satellites GOES) permit good estimations of ionization rates and electron number densities. Atomic oxygen and ozone profiles which lead to model electron number density profiles $N_{\mathrm{e}}(h)$ consistent with observations and which, consequently, are the most appropriate for polar mesospheric altitudes under solar proton event conditions have been presented by Osepian et al. $(2008,2009 a)$.

In this study, the theoretical PGI model of the D-region has been modified to examine the structure of the lower ionosphere during quiet conditions and at any geographic latitude. In order to minimize possible errors in estimation of ionization rates by solar electromagnetic radiation which might be neglected during solar proton precipitation, a new, more accurate algorithm for computation of solar radiation intensity at different levels of solar activity has been applied. For this aim the dependences of the solar radiation intensity on the solar index $F_{10.7}$ derived by Nusinov (1992) for each wavelength range of the solar spectrum were used. The model of the lower ionosphere consists of the following modules:

- model of the neutral atmosphere's major constituents (MSIS-2000) (Hedin, 1991; Picone et al., 2002);

- height profiles of the minor neutral constituents;

- algorithm for calculating solar radiation intensity in different wavelength ranges;

- algorithm for calculating the ionization rates taking into account all sources of the ionization during quiet periods;

- algorithm for calculating concentration of minor neutral constituents for different solar zenith angles and different altitudes;

- ion chemistry model (Smirnova et al., 1988).

This type of model construction provides good opportunities for model modification when new data on ionospheric and mesospheric parameters, ionization sources and chemical processes appear. 
The ion chemical model, implemented as a separate module in the theoretical model of ionization-recombination cycle for D-region, has been developed by Smirnova et al. (1988). In this model the simple cluster ions $\mathrm{NO}^{+} \cdot\left(\mathrm{H}_{2} \mathrm{O}\right)_{n}$ and $\mathrm{O}_{2}^{+} \cdot\left(\mathrm{H}_{2} \mathrm{O}\right)_{n}$, formed from the primary ions $\mathrm{NO}^{+}$and $\mathrm{O}_{2}^{+}$, are combined into a cluster family $1, \mathrm{Cl}_{1}^{+}$. Their recombination coefficient with electrons is typically $2 \times 10^{-6} \mathrm{~cm}^{3} \mathrm{~s}^{-1}$. Proton hydrates $\mathrm{H}^{+} .\left(\mathrm{H}_{2} \mathrm{O}\right)_{n}$, are combined into a cluster family $2, \mathrm{Cl}_{2}^{+}$. They recombine with electrons about five times faster than ions from $\mathrm{Cl}_{1}^{+}$. The primary negative ions $\mathrm{O}_{2}^{-}$and $\mathrm{O}^{-}$initiate series of reactions with neutral constituents and produce complex negative ions, in particular $\mathrm{O}_{3}^{-}, \mathrm{O}_{4}^{-}, \mathrm{CO}_{2}^{-}$, $\mathrm{CO}_{4}^{-}$. These ions are intermediate, have short life time and low concentrations. However, their role in formation of the major intermediate ion $\mathrm{CO}_{3}^{-}$and the stable $\mathrm{NO}_{3}^{-}$ion, which is formed from $\mathrm{CO}_{3}^{-}$, is very important.

In the ion-chemical model that was used in this study, the efficiency of the hydration chains of $\mathrm{NO}^{+}$and $\mathrm{O}_{2}^{+}$and reaction chains forming intermediate negative ions $\mathrm{CO}_{3}^{-}$from the primary ions $\mathrm{O}_{2}^{-}$and $\mathrm{O}^{-}$are substituted by the effective parameters $B\left(\mathrm{~N}^{+}\right), B\left(\mathrm{O}_{2}^{+}\right), B\left(\mathrm{O}_{2}^{-}\right)$and $B\left(\mathrm{O}^{-}\right)$which are determined by the expressions (A1)-(A4) given in the Appendix. The transformation of $\mathrm{Cl}_{1}^{+}$to proton hydrates $\mathrm{H}^{+} \cdot\left(\mathrm{H}_{2} \mathrm{O}\right)_{\mathrm{n}}$ is described by the expression (A5). The rate constants for positive and negative ion reactions are given in Tables A1 and A2, respectively.

The input parameters for the model are date, local time, geomagnetic latitude, geographic latitude and longitude, temperature, altitude profiles for $\mathrm{O}_{2}, \mathrm{~N}_{2}$, height profiles for minor neutral constituents $\left(\mathrm{NO}, \mathrm{O}, \mathrm{O}_{3}, \mathrm{H}_{2} \mathrm{O}, \mathrm{O}_{2}\left(1 \Delta_{\mathrm{g}}\right), \mathrm{NO}_{2}\right.$, $\mathrm{CO}_{2}$ ) for noon and midnight LT with a vertical step of $1 \mathrm{~km}$ and solar activity index $F_{10.7}$. Due to the short lifetime of ions and electrons in the D-region, dynamical and transport effects are ignored. The continuity equations for the main positive ions $\left(\mathrm{NO}^{+}, \mathrm{O}_{2}^{+}, \mathrm{Cl}_{1}^{+}, \mathrm{Cl}_{2}^{+}\right)$and negative ions $\left(\mathrm{O}_{2}^{-}\right.$, $\mathrm{O}^{-}, \mathrm{CO}_{3}^{-}, \mathrm{NO}_{3}^{-}$) are solved under steady-state conditions. Electron number density $N_{\mathrm{e}}$ is calculated as the difference between positive and negative ion number densities. Under equilibrium conditions, effective recombination coefficient $\alpha_{\text {eff }}$ is determined from the continuity equation for electrons $Q(h)=\alpha_{\mathrm{eff}} \cdot N_{\mathrm{e}}^{2}$. More detailed description of the ionchemical model is given by Smirnova et al. (1988), Osepian et al. (2008).

The aim of this study is

- to model electron density profiles in the quiet lower ionosphere using $\mathrm{NO}, \mathrm{O}, \mathrm{O}_{3}$, and $\mathrm{H}_{2} \mathrm{O}$ profiles with different values of concentration and evaluate their influence on the electron number density at the different altitudes;

- to examine the response of the model to changes of the solar zenith angle, solar activity and season;
- to verify the modeled $N_{\mathrm{e}}(h)$-profiles with experimental data in the sunlit summer and winter ionosphere and to determine which profiles of minor neutral constituents lead to the best agreement between theoretical and experimental $N_{\mathrm{e}}$ values for chosen situations.

A brief description of the ionisation sources in quiescent conditions is presented in Sect. 2. The height profiles of the mesospheric minor neutral species $\left(\mathrm{NO}, \mathrm{O}, \mathrm{O}_{3}, \mathrm{H}_{2} \mathrm{O}\right)$ are given in Sect. 3. Model simulations of the ionospheric parameters in the daytime summer and winter ionosphere are given in Sect. 4. Section 5 contains discussion and conclusions.

\section{Sources of ionization in the quiescent conditions}

\subsection{Daytime conditions}

Solar radiation is the leading source of ion production in the daytime ionosphere under quiet geophysical conditions. Ionization of the D-region during the daytime is determined by several wavelength ranges, namely, hard X-rays (less than $1 \mathrm{~nm})$, soft $X$ rays $(1-10 \mathrm{~nm}), \mathrm{Ly}-\beta(102.6 \mathrm{~nm})$ and Ly$\alpha(121.6 \mathrm{~nm})$ emissions, the continuum radiation at 102.6 $111.8 \mathrm{~nm}$. The ion production rate at the altitude $h$ is determined by the classic formula:

$$
\begin{aligned}
Q_{\mathrm{ph}}(h)= & \sum_{\lambda} J_{\infty}(\lambda) \sum_{i} \sigma_{\mathrm{i}}(\lambda) n_{\mathrm{i}}(h) \\
& \exp \left\{-\sum_{\mathrm{i}} \bar{\sigma}_{\mathrm{i}}(\lambda) \int_{\mathrm{h}}^{\infty} N_{\mathrm{i}}(z) C h(\chi) d z\right\}
\end{aligned}
$$

where $J_{\infty}(\lambda)$ is the intensity of the solar radiation on the top of the atmosphere at wavelength $\lambda, \sigma_{\mathrm{i}}(\lambda)$ is the ionization cross section, $\bar{\sigma}_{\mathrm{i}}(\lambda)$ is the absorption cross section, $n_{\mathrm{i}}(h)$ is the concentration of the neutral component at the altitude $h$ and $\int_{\mathrm{h}}^{\infty} N_{\mathrm{i}}(z) C h(\chi) d z$ is the content of absorbing component in the atmosphere column above the given altitude $h$, $C h(\chi)$ is the Chapman grazing incidence function, which can be calculated according to Smith and Smith (1972). Ionization and absorption cross sections have been evaluated for different wavelengths by Nicolet and Aikin (1960); IvanovKholodniy and Velichanskiy (1973); Torr et al. (1979); Rees (1989); Nusinov (1986, 1992).

For each wavelength range of the solar spectrum, solar radiation intensity has a different dependence on the level of solar activity where the latter can be described by the parameter $F_{10.7}$. For calculation of solar X-ray and EUVradiation intensities as functions of solar activity a method developed by Nusinov (1992) has been applied. According to this method, solar radiation intensity in the wavelength range $10-102.6 \mathrm{~nm}$ can be calculated using the expression:

$J_{\lambda}\left(F_{10.7}\right)=R_{\lambda} \times J_{58.4}\left(F_{10.7}\right)$ 
where the wavelength of $58.4 \mathrm{~nm}$ is assumed to be a principal line. The value $R_{\lambda}$ for every line is calculated using the following expression with coefficients $a_{\lambda}$ and $b_{\lambda}$ as given by Nusinov (1992):

$R_{\lambda}=a_{\lambda}+b_{\lambda} J_{58.4}\left(F_{10.7}\right)$

The order and units of $J_{58.4}\left(F_{10.7}\right)$ are $10^{9} \mathrm{~cm}^{-2} \mathrm{~s}^{-1}$. It depends on the solar activity according to the expression:

$$
\begin{aligned}
J_{58.4}\left(F_{10.7}\right)= & 1.38+0.111\left(F_{b}-60\right)^{0.667} \\
& +0.0538\left(F_{10.7}-F_{b}\right)^{0.667} .
\end{aligned}
$$

The photoionization and photo-absorption cross-sections for $\mathrm{O}_{2}, \mathrm{~N}_{2}$ and $\mathrm{O}$ within the wavelength range $10-102.6 \mathrm{~nm}$ are taken according to Torr et al. (1979) and Rees (1989).

Variation of the Ly- $\alpha$ intensity as a function of solar activity is given by the expression:

$$
\begin{aligned}
J_{121.6}\left(F_{10.7}\right)= & \left\{134+39.9\left(F_{\mathrm{b}}-60\right)^{0.667}\right. \\
& \left.+5.47\left(F_{10.7}-F_{\mathrm{b}}\right)^{0.667}\right\} \times 10^{9}
\end{aligned}
$$

where, $F_{\mathrm{b}}$ is the background flux of the solar radio emission at the wavelength of $10.7 \mathrm{~cm}$. Variations of $F_{\mathrm{b}}$ during the solar cycle are defined as

$F_{\mathrm{b}}=\sum_{i=0}^{4}\left[A_{\mathrm{i}} \cos (2 \pi i t / T)+B_{\mathrm{i}} \sin (2 \pi i t / T)\right]$

with the coefficients $A_{\mathrm{i}}(82.1,-19.6,1.778,2.59,-2.33)$ and $B_{\mathrm{i}}(0,10.55,-0.956,3.104,-0.925)$ incorporated into the program from Nusinov (1992). $T$ is the duration of the solar cycle, $t$ is the number of years from the solar cycle minimum.

The X-ray intensity for varying solar activity conditions can be expressed as

$J_{\lambda_{1}-\lambda_{2}}\left(F_{10.7}\right)=J_{\lambda_{1}-\lambda_{2}}^{0}\left[I_{\mathrm{r}}\left(F_{10.7}\right) / 16.8\right]^{d}$

with parameter $d$ determined as

$d=0.22+1.56 / \lambda_{2}$

In Eq. (7) $I_{\mathrm{r}}\left(F_{10.7}\right)$ is the energy flux given in $\mu \mathrm{W} \mathrm{m} \mathrm{m}^{-2}$ within the wavelength interval $0.8-2.0 \mathrm{~nm}$. $I_{\mathrm{r}}\left(F_{10.7}\right)$ varies with the solar activity according to:

$I_{\mathrm{r}}\left(F_{10.7}\right)=0.29 F_{10.7}-18$

The values of $J_{\lambda 1-\lambda 2}^{0}$ and the absorption and ionization crosssections for all intervals of the X-ray spectrum are given by Nusinov $(1986,1992)$. The intensity of the continuum radiation within the wavelength range $102.7-111.8 \mathrm{~nm}$ depends on the solar activity according to Paulsen et al. (1972).

\subsection{Nocturnal conditions}

For calculation of the ion-production rate in nocturnal conditions, a semi-empirical approach developed by Kashirin (1986) has been applied. This approach is based on the combined analysis of theoretical and experimental data on spatial and time variations of the scattered radiation and provides the total isotropic flux at an altitude of $300 \mathrm{~km}$ for four wavelengths, i.e. $30.4 \mathrm{~nm}(\mathrm{He} \mathrm{II}), 58.4 \mathrm{~nm}$ (He I), $121.6 \mathrm{~nm}$ (Ly$\alpha)$, and $102.6 \mathrm{~nm}(\mathrm{Ly}-\beta)$. The flux is a function of solar zenith angle $\chi$, solar activity $F_{10.7}$ and season. The ion production rate due to scattered radiation at wavelength $\lambda$ at altitudes below $300 \mathrm{~km}$ is given by

$q^{\lambda}=\sigma_{\lambda}^{\mathrm{i}} n_{\mathrm{i}} \int_{0}^{2 \pi} d \phi \int_{0}^{\pi} \sin \theta d \theta J_{\lambda}(\theta, \phi) \exp \left[-\tau_{\lambda} \sec \theta\right]$

where

$\tau_{\lambda}=\sigma_{\lambda}^{\mathrm{a}} \int_{\mathrm{h}}^{h_{\max }}\left[\mathrm{O}_{2}\right](h) d h$.

In Eqs. (10) and (11) $\sigma_{\lambda}^{\mathrm{i}}$ is the ionization cross section at wavelength $\lambda, \sigma_{\lambda}^{\mathrm{a}}$ is the absorption cross section, $\theta$ is the zenith angle, $\phi$ is the azimuth angle, $n_{\mathrm{i}}$ is the concentration of the component that absorbs and scatters the radiation at the characteristic altitude $h$, i.e. $\mathrm{NO}$ for $\mathrm{Ly}-\alpha$ radiation, $\mathrm{O}_{2}$ for $\mathrm{Ly}-\beta$ line, $\mathrm{O}_{2}, \mathrm{~N}_{2}$ and $\mathrm{O}$ for $\mathrm{He} \mathrm{I}$ and $\mathrm{He}$ II lines. The scattered radiation at $300 \mathrm{~km}$ is assumed to be isotropic over the downward hemisphere $J_{\lambda}(\theta, \phi)=J_{\lambda}$.

The model takes into account the ionization by galactic cosmic rays, whose intensity depends on geomagnetic latitude and solar activity, $F_{10.7}$, according to Swider (1979).

\section{The minor neutral constituents}

Ion composition and ion molecular reactions in the D-region are directly coupled to the local concentration of the longlived minor neutral species including $\mathrm{NO}, \mathrm{H}_{2} \mathrm{O}, \mathrm{O}$ and $\mathrm{O}_{3}$. Nitric oxide, NO, is the most important component for the D-region ion chemistry under quiet conditions. Ions $\mathrm{NO}^{+}$ are the main source of cluster ions in the quiet lower ionosphere. Molecules of NO actively participate in complex photochemical reactions, resulting in formation of the final ions $\mathrm{NO}_{3}^{-}$. Experimental data demonstrate the dependence of NO number density on latitude, solar activity and season (Grossmann et al., 1985; Siskind and Rusch, 1992; Siskind et al., 1997, 1998). Theoretical studies have revealed the processes controlling photochemical sources and sinks of nitric oxide (Ogawa and Shimazaki, 1975; Siskind et al., 1997, 1998). The reactions that are responsible for production of odd nitrogen, i.e. nitrogen oxide and atomic nitrogen, in the lower thermosphere, are summarized in Table 1. 
Table 1. Reactions responsible for odd nitrogen production (Ogawa and Shimazaki, 1975; Marov et al., 1996; DeMore et al., 1994; Sander et al., 2003).

\begin{tabular}{lll}
\hline No. & Reaction & Rate constant, $\mathrm{cm}^{3} \mathrm{~s}^{-1}$ \\
\hline$(\mathrm{R} 1)$ & $\mathrm{N}_{2}+h v(800-1000 \AA) \rightarrow \mathrm{N}+\mathrm{N}$ & $1.90 \times 10^{-8}$ \\
$(\mathrm{R} 2)$ & $\mathrm{N}_{2}+h v(1-800 \AA) \rightarrow \mathrm{N}+\mathrm{N}$ & $4.53 \times 10^{-8}$ \\
$(\mathrm{R} 3)$ & $\mathrm{N}_{2} \mathrm{O}+h v(630-2490 \AA) \rightarrow \mathrm{NO}+\mathrm{N}$ & $3.71 \times 10^{-8}$ \\
$(\mathrm{R} 4)$ & $\mathrm{NO}_{2}+h v(2440-3980 \AA) \rightarrow \mathrm{NO}+\mathrm{O}$ & $8.30 \times 10^{-3}$ \\
$(\mathrm{R} 5)$ & $\mathrm{NO}_{2}+h v(1027-2440 \AA) \rightarrow \mathrm{NO}+\mathrm{O}\left({ }^{1} \mathrm{D}\right)$ & $1.22 \times 10^{-4}$ \\
$(\mathrm{R} 6)$ & $\mathrm{N}_{2}+p^{+} \rightarrow \mathrm{N}\left({ }^{2} \mathrm{D}\right)+\mathrm{N}\left({ }^{4} \mathrm{~S}\right)+p^{+}$ & - \\
$(\mathrm{R} 7)$ & $\mathrm{N}_{2}+e \rightarrow \mathrm{N}\left({ }^{2} \mathrm{D}\right)+\mathrm{N}\left({ }^{4} \mathrm{~S}\right)+e$ & - \\
$(\mathrm{R} 8)$ & $\mathrm{N}_{2}^{+}+\mathrm{O} \rightarrow \mathrm{N}\left({ }^{2} \mathrm{D}\right)+\mathrm{NO}+$ & $1.4 \times 10^{-10} \cdot(300 / T)^{0.44}$ \\
$(\mathrm{R} 9)$ & $\mathrm{NO}^{+}+e \rightarrow \mathrm{N}\left({ }^{2} \mathrm{D}\right)+\mathrm{O}$ & $4.2 \times 10^{-7}(300 / T)^{0.85}$ \\
$(\mathrm{R} 10)$ & $\mathrm{N}\left({ }^{2} \mathrm{D}\right)+\mathrm{O}_{2} \rightarrow \mathrm{NO}+\mathrm{O}$ & $1.5 \times 10^{-11} \cdot \exp (-3600 / T)$ \\
\hline
\end{tabular}

$p^{+}$is primary proton, $e$ is secondary electron.

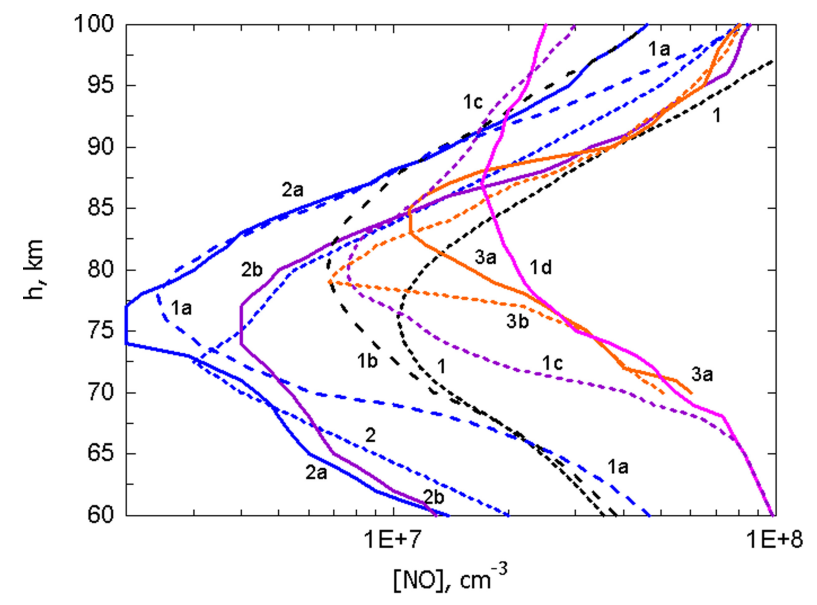

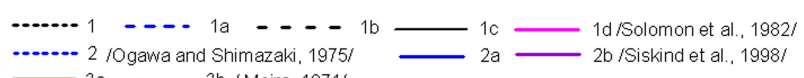

Fig. 1a. Examples of nitric oxide number density profiles during the daytime (solar zenith angle below $90^{\circ}$ ) retrieved from photochemical models 1, 1a, 1b, 1c, 1d (Solomon et al., 1982) and experimental measurements 2 (Ogawa and Shimazaki, 1975), 2a, 2b (Siskind et al., 1998), 3a, 3b (Meira, 1971).

Reactions (R1)-(R5) are responsible for photo dissociation of $\mathrm{N}_{2}, \mathrm{~N}_{2} \mathrm{O}$ and $\mathrm{NO}_{2}$ in quiet conditions. At high latitudes, odd nitrogen can be produced by the collisions between nitrogen and relativistic protons (Reaction R6) or secondary electrons (Reaction R7). According to Porter et al. (1976), during the Reaction (R6), $45 \%$ of nitrogen atoms are in the state $\left[\mathrm{N}\left({ }^{4} \mathrm{~S}\right)\right]$ and $55 \%$ are in the excited state $\left[\mathrm{N}\left({ }^{2} \mathrm{D}\right)\right]$. Since there is a strong coupling between the neutral and ionized species, the reactions involving ionic species (Reactions R8, R9) are important to increase the concentration of NO through the Reaction (R10). Downward transport from the thermosphere is the main source of NO in the mesosphere. This has been confirmed by Halogen Occultation

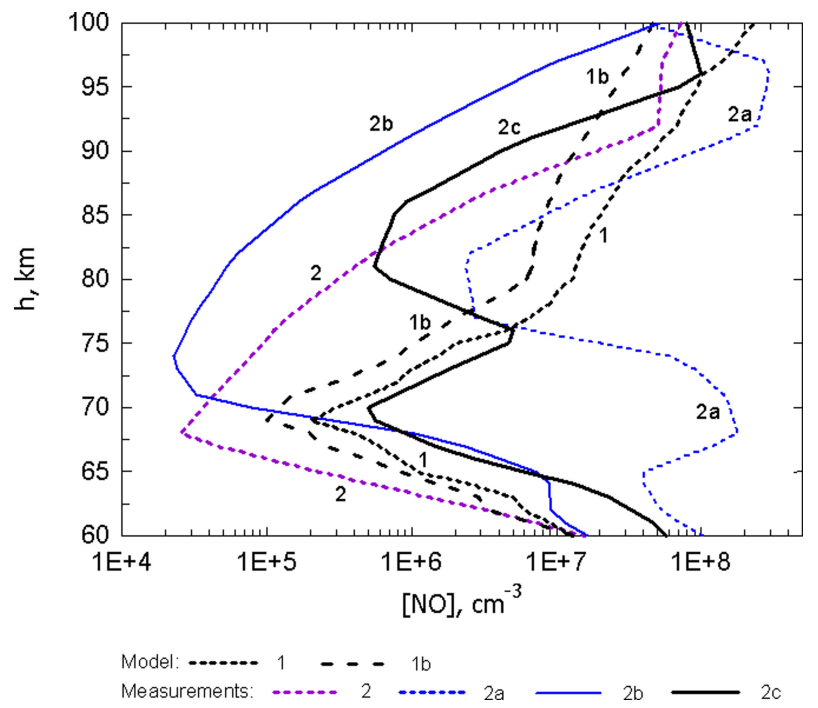

Fig. 1b. Examples of nitric oxide number density profiles during the nighttime (solar zenith angle above $94^{\circ}$ ) retrieved from photochemical models 1, 1b (Solomon et al., 1982) and measurements 2, 2a, 2b, 2c (HALOE http://haloe.gats-inc.com/home/index.php).

experiment (HALOE) on board the Upper Atmosphere Research Satellite (UARS) which has demonstrated significant coupling between the NO layers in the thermosphere and the middle atmosphere (Siskind and Russel, 1996; Siskind et al., 1998). Examples of NO profiles, including available profiles with minimum and maximum $\mathrm{NO}$ concentrations, are shown for daytime and nighttime in Fig. 1a and b. The discrepancies in the numerical density for daytime NO profiles (Fig. 1a) might be about one order of magnitude. Difference in the nighttime NO concentrations (Fig. 1b) might be a few orders of magnitude. The nighttime profiles 1 and 1b (Fig. 1b) have been calculated from the respective daytime profiles 1 and 1a (Fig. 1a) using the coefficients from Ogawa and Shimazaki (1975). The NO profiles 2, 2a, 2b and 


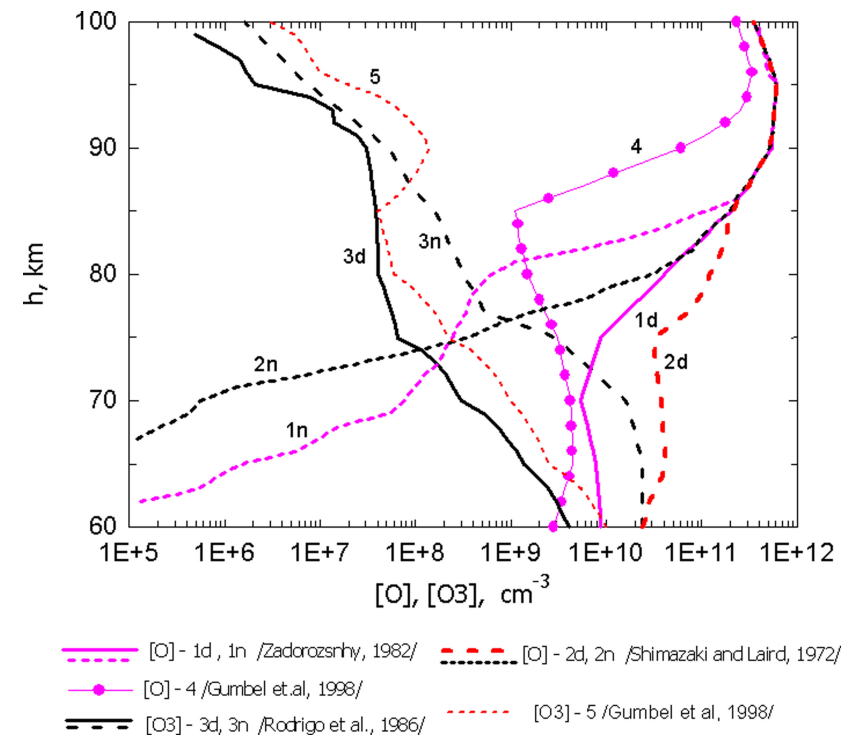

Fig. 2a. Profiles of atomic oxygen and ozone in the sunlit and nocturnal mesosphere $(\mathrm{d}-$ day; $\mathrm{n}$ - night).

2c have been obtained from the HALOE instrument (2011): (http://haloe.gats-inc.com/home/index.php). All profiles of nitric oxide presented in Fig. 1a and b have been used as inputs for modeling the electron density profiles.

Modern knowledge on the height distribution of atomic oxygen in the quiet mesosphere, especially below $80 \mathrm{~km}$, is mainly based on the results of the theoretical estimations derived from diffusion-photochemical models (Shimazaki and Laird, 1970, 1972; Turco and Sechrist, 1972; Keneshea et al., 1979; Zadorozhny, 1982; Brasseur and Offermann, 1986; Murray and Plane, 2005). The atomic oxygen is controlled by both photochemical and dynamical processes (turbulence, molecular and eddy diffusions, vertical and meridional transports). During the daytime, concentrations of atomic oxygen at altitudes below $80 \mathrm{~km}$ are about $10^{10} \mathrm{~cm}^{-3}$. When the solar zenith angle exceeds $96^{\circ}$, photochemical production of atomic oxygen stops and its number density drops dramatically.

Ozone is continually formed and destroyed in the mesosphere. Measurements (Zommerfields et al., 1989; Fussen et al., 2000; Kaufmann et al., 2003; Polyakov et al., 2005) and theoretical investigations (Shimazaki and Laird, 1970, 1972; Thomas and Bowman, 1972; Zadorozhny, 1982; Rodrigo et al., 1986; Sandor et al., 1997) show substantial diurnal variations of ozone concentration with maximum values at nighttime. Theoretical values of ozone numerical density are rather close to experimental values. It should be noted that differences between maximum and minimum values of ozone, derived in different theoretical models for the similar conditions, are not as large as for NO and O concentrations. During the nighttime, differences in theoretical estimations of both atomic oxygen and ozone concentration

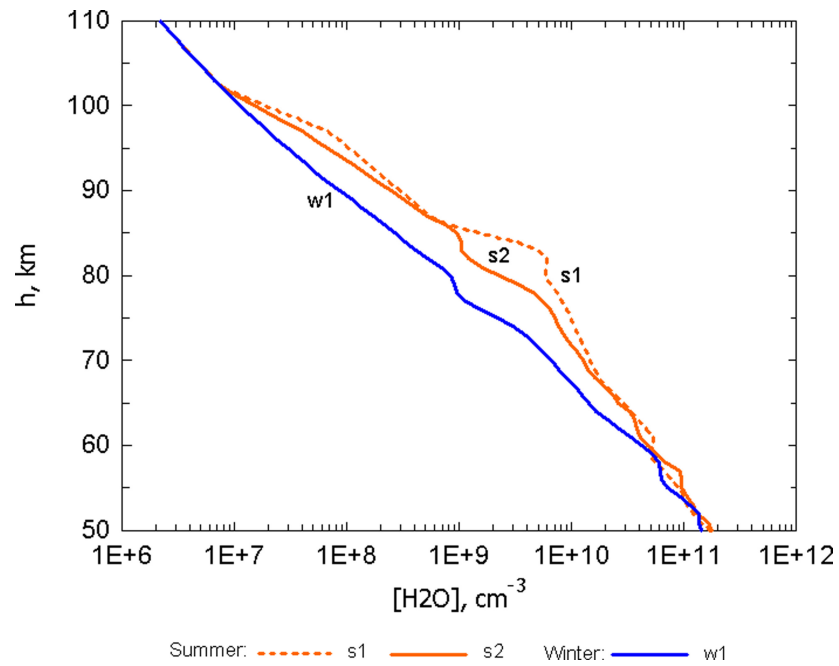

Fig. 2b. Profiles of water vapor number density (HALOE http: //haloe.gats-inc.com/home/index.php). Curve w1 - for winter. Curves s1, s2 - for summer.

are more pronounced than during the daytime. Profiles of atomic oxygen and ozone at local noon and midnight presented in Fig. 2a are used as input parameters into the theoretical model of the D-region. The $\mathrm{O}$ profiles 1 and 2 at altitudes between 60 and $85 \mathrm{~km}$ are taken from the models by Zadorozhny (1982) and Shimazaki and Laird (1972). The O profile above $85 \mathrm{~km}$ is taken from the MSIS-2000 neutral atmosphere model. The $\mathrm{O}_{3}-3$ profiles are taken from the model by Rodrigo et al. (1986). The profiles O-4 and $\mathrm{O}_{3}-5$ at altitudes above $70 \mathrm{~km}$ are taken from Gumbel et al. (1998). They have been arbitrarily extrapolated downward to $60 \mathrm{~km}$.

Water vapor profiles are taken from measurement by the HALOE instrument (Fig. 2b).

\section{Results}

To test the quality of the model and to determine which profiles of minor neutral constituents are the most appropriate for mesospheric altitudes under quiet conditions, simulated electron density profiles are compared with electron densities obtained from rocket experiments in summer and winter for solar zenith angles less than $80^{\circ}$ (day) and larger than $99^{\circ}$ (night). Rocket data obtained by the Faraday rotation method in the Volgograd region (geographic coordinates are $48.5^{\circ} \mathrm{N}, 45.6^{\circ} \mathrm{E}$; geomagnetic latitude is $43.1^{\circ} \mathrm{N}$ ) have been taken from catalogues presented by Danilov and Ledomskya (1983), Smirnova et al. (1990).

Figure $3 \mathrm{a}$ shows electron density profiles in the altitude range between 70 and $90 \mathrm{~km}$ measured near Volgograd under similar geophysical conditions, i.e. solar zenith angles of $30^{\circ}-52^{\circ}$, low solar activity $\left(F_{10.7}=70-82\right)$, summertime. The electron density profile for the altitude interval between 80 and $100 \mathrm{~km}$ at $37.8^{\circ} \mathrm{N}$, geomagnetic latitude $49.3^{\circ} \mathrm{N}$, 


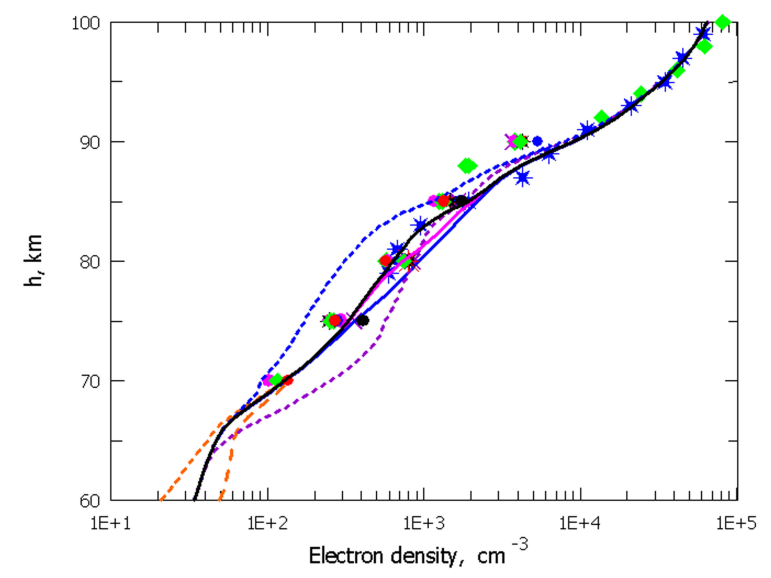

Rocket: $29.07 .1976 ; X=30.4,12.5 \mathrm{LT}-29.07 .1976, X=44.6,09.30 \mathrm{LT} \quad 29.07 .1976, X=44.6,14.8 \mathrm{LT}$ * $19.08 .1976, X=36 \gg 19.08 .1976, X=50.8$ and $X=52 \quad \times 20.08 .1976, X=37.1 \quad 20.08 .1976, X=51$ * $10.08 .1973, X=35$ - from Ginther and Smith, 1975

29.07.1976, X=44.6. Model O -1d, O3-3d, H2O-s1: ........ NO-1a — NO-1 ...... NO-1d Model O-1d, O3-3d, NO-1: - $\mathrm{H}_{2} \mathrm{O}-\mathrm{s} 1-\mathrm{H} 2 \mathrm{O}-\mathrm{s} 2-\mathrm{H}_{2} \mathrm{O}-\mathrm{w} 1$ Model NO-1, H2O-s1, O3-3d: _ - - O-2d _...... O- 4

Fig. 3a. Electron number density profiles from rocket experiments (symbols) and the model (dashed and solid curves without symbols). Solar zenith angles for the rocket data $30.4^{\circ}-52^{\circ}$. Modeled profiles are calculated for 29 July 1976 , solar zenith angle $44.6^{\circ}$, $F_{10.7}=70$.

solar zenith angle $\chi=35^{\circ}$, has been taken from Ginther and Smith (1975). Modeled electron density profiles have been calculated for 29 July $1976, \chi=44.6^{\circ}, F_{10.7}=70$ at $48.5^{\circ} \mathrm{N}, 45.6^{\circ} \mathrm{E}$ using all profiles of the minor neutral species presented in Figs. 1a, $2 \mathrm{a}$ and $\mathrm{b}$. Samples of the $N_{\mathrm{e}}(h)$-profiles calculated for O-1d, $\mathrm{O}_{3}-3 \mathrm{~d}$ (Fig. 2a), $\mathrm{H}_{2} \mathrm{O}-$ s1 (Fig. 2b), but for different nitric oxide profiles (1a, 1 and 1d), are shown in Fig. 3a by the short dashed lines. It can be seen that modeled values of electron density respond to changes in the nitric oxide concentration only in the altitude interval between 68 and $85 \mathrm{~km}$, since total ionization rate at these altitudes is mainly due to ionization of NO molecules by Ly- $\alpha$ emission (Fig. 3b). The difference between NO concentration for profiles 1a and 1d (Fig. 1a) in the altitude range $70-80 \mathrm{~km}$ can reach an order of magnitude. This leads to changes of electron number density of 2.8-3.5 times. At altitudes above $85 \mathrm{~km}$, ionization near noon is produced mainly by other lines of the solar spectrum (Fig. 3b) and variations of NO concentration by factors $3-5$ does not change the modeled values of electron density.

In Fig. 3a the influence of water vapor and atomic oxygen concentrations on the electron number density are shown. A decrease of water vapor concentration, by more than a factor of 2 at all altitudes of the mesosphere $\left(\mathrm{H}_{2} \mathrm{O}-\mathrm{s} 1\right.$ and $\mathrm{H}_{2} \mathrm{O}$-w 1 in Fig. 2b) leads to an increase of electron number density only in the height range between 73 and $85 \mathrm{~km}$ where the water concentration changes by more than factor of 5 . An influence of atomic oxygen concentration (O-2d and O-4 in Fig. 2a) on electron density is seen only at the altitudes be-

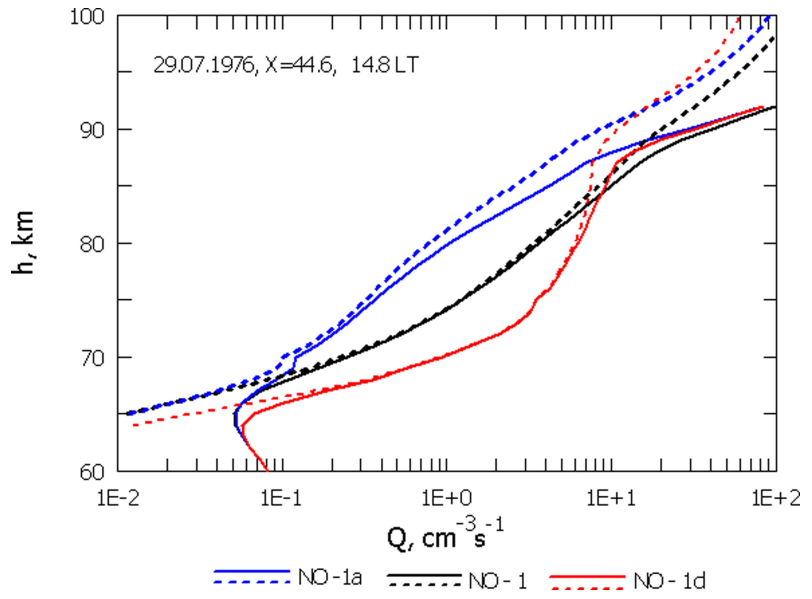

Fig. 3b. Profiles of the ionization rate of nitric oxide by Ly- $\alpha$ emission (dashed lines) and total ionization rate (solid lines) for 29 July 1976 , solar zenith angle $44.6^{\circ}$ on the basis of NO-1a, 1 and $1 \mathrm{~d}$ profiles.

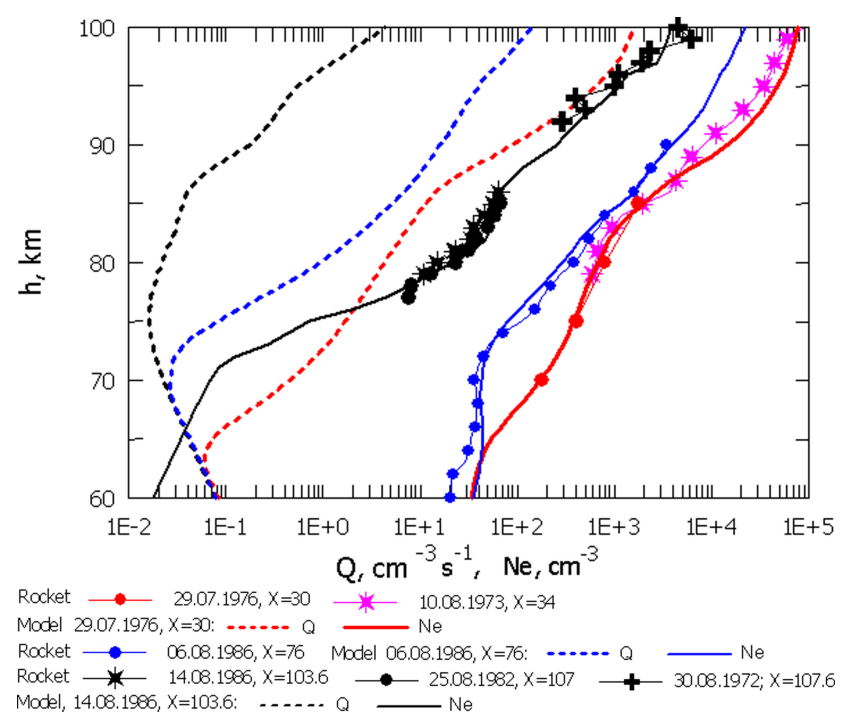

Fig. 4. Electron density profiles measured at different solar zenith angles under low solar activity $F_{10.7}=67-85$ (symbols). Ionization rate (dashed lines) and electron number density (solid lines without symbols) modeled for the same conditions on the basis of NO-1 profile (Solomon et al., 1982).

low $70 \mathrm{~km}$ (red dashed lines). Above $70 \mathrm{~km}$, both high (O-2d profile) and very low (O-4 profile) values of oxygen compared to O-1d profile, don't change electron number density at daytime. Changes of ozone concentration, between the $\mathrm{O}_{3}$ $3 \mathrm{~d}$ profile and the $\mathrm{O}_{3}-5$ profile, do not influence $N_{\mathrm{e}}$ values at altitudes above $70 \mathrm{~km}$. Below $70 \mathrm{~km}$, an increase of ozone by 3-4 times leads to a decrease of electron number density by less than 1.3 times. The influence of ozone on electron density is not shown in Fig. 3a. Comparing the summer modeled and experimental electron number densities, it can be 


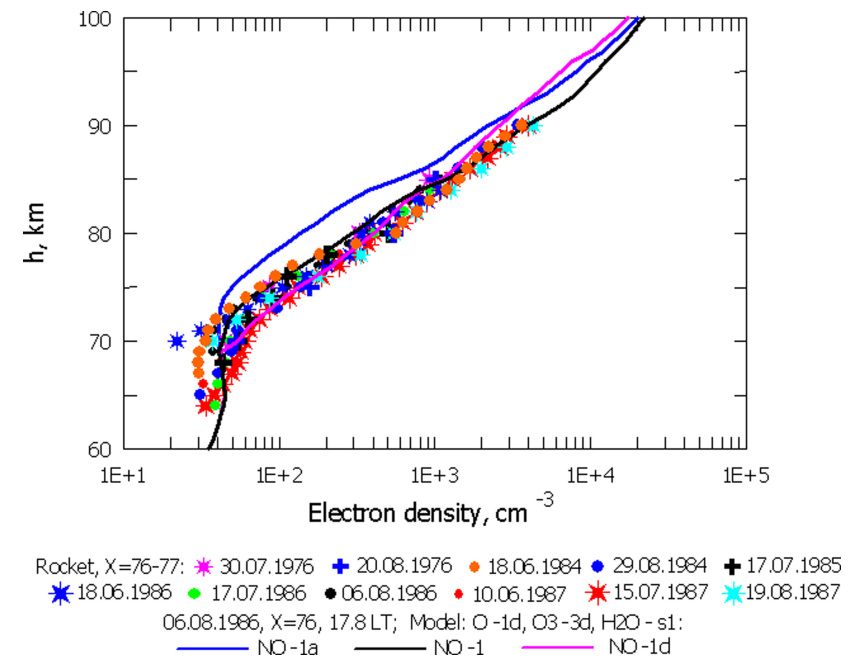

Fig. 5a. Electron number density profiles from rocket experiments (symbols) and the model (solid curves without symbols) during low solar activity. Solar zenith angles for the rocket data $76^{\circ}-77^{\circ}$. Modeled profile is calculated for 6 August 1986, solar zenith angle $76^{\circ}, F_{10.7}=70$ on the basis of different NO-1 profiles (solid lines) (Solomon et al., 1982).

seen that just the profiles of water vapor measured in summer (the $\mathrm{H}_{2} \mathrm{O}-\mathrm{s} 1$ or $\mathrm{H}_{2} \mathrm{O}-\mathrm{s} 2$ ) and the daytime profile NO-1 are required in order to model electron density profiles which are consistent with observations at $\chi=30-50^{\circ}$ during low solar activity. Below, all model $N_{\mathrm{e}}(h)$-profiles for the sunlit summer ionosphere are computed on the basis of the input O-1d (Zadorozhny, 1982), $\mathrm{O}_{3}$-3d (Rodrigo et al., 1986) and $\mathrm{H}_{2} \mathrm{O}-$ s1 (HALOE) profiles.

The ionization rates and corresponding electron density profiles have been modeled for low solar activity at different solar zenith angles (29 July $1976, \chi=30.4^{\circ}$ and $44.6^{\circ}$; 18 July $1984, \chi=76^{\circ} ; 14$ August $1986, \chi=103.6^{\circ}$ ) as the respective experimental rocket data were available (Fig. 4). They are shown by dashed and solid lines. Experimental values of electron density are shown by symbols. It can be seen that the modeled values of the electron density reproduce experimental $N_{\mathrm{e}}$ values at all zenith angles. For daytime, the NO-1, O-1d and $\mathrm{O}_{3}-3 \mathrm{~d}$ profiles have been used as input into the model. For nighttime $\left(\chi=103.6^{\circ}\right)$, the modeled $N_{\mathrm{e}}(h)$ profile (black solid line ) has been obtained on the basis of the $\mathrm{O}-1 \mathrm{n}, \mathrm{O}_{3}-3 \mathrm{n}$ and NO-2 profiles.

In Fig. 5a eleven experimental $N_{\mathrm{e}}$ profiles for summer (June-August), measured during afternoon, at solar zenith angles of $76^{\circ}-77^{\circ}$, and during low solar activity $\left(F_{10.7}=67-\right.$ $85)$, are reproduced from a catalog of rocket data. The model $N_{\mathrm{e}}(h)$ profiles have been calculated for 6 August 1986 at $\chi=76^{\circ}$ on the basis of the NO-profiles $1 \mathrm{a}, 1$ and $1 \mathrm{~d}$. It is noted that at this zenith angle, considerable influence of NO on electron production rate (black lines in Fig. 5b) and electron density is seen at the altitudes between 70 and $95 \mathrm{~km}$.

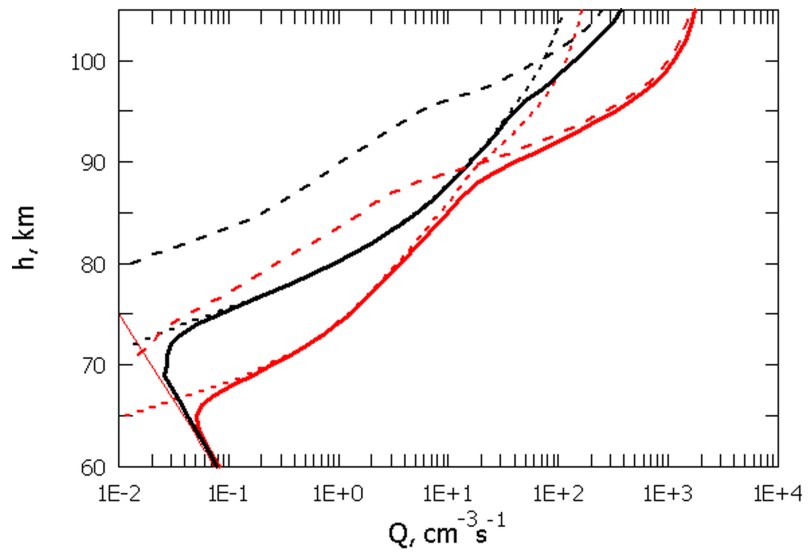

$$
\begin{aligned}
& \text { 29.07.1976, } X=44.6, F(10.7)=70 \text {, NO }-1 \text { : — Ionization rate by cosmic rays } \\
& \text {... Ionization rate of } \mathrm{NO}_{\text {by }} \mathrm{Ly}_{-} \text {alpha emission } \\
& \text { - - - Ionization rate of } \mathrm{O} 2 \text { by all sources of solar radiation } \\
& \text { - Production rate of electrons in the lower ionosphere by all sources } \\
& \text { 06.08.1986, } X=76, F(10.7)=70 \text {, NO -1: . . . . I I Inization rate of } N O \text { by } L Y \text { _alpha emission } \\
& \text { - - - lonization rate of } \mathrm{O} 2 \text { by all sources of solar radiation } \\
& \text { - Production rate of electrons in the lower ionosphere by all sources }
\end{aligned}
$$

Fig. 5b. Profiles of the ionization rate for 29 July 1976, solar zenith angle $44.6^{\circ}$ (red lines) and for 6 August 1986, solar zenith angle $76^{\circ}$ (black lines) on the basis of the NO-1 profile (Solomon et al., 1982).

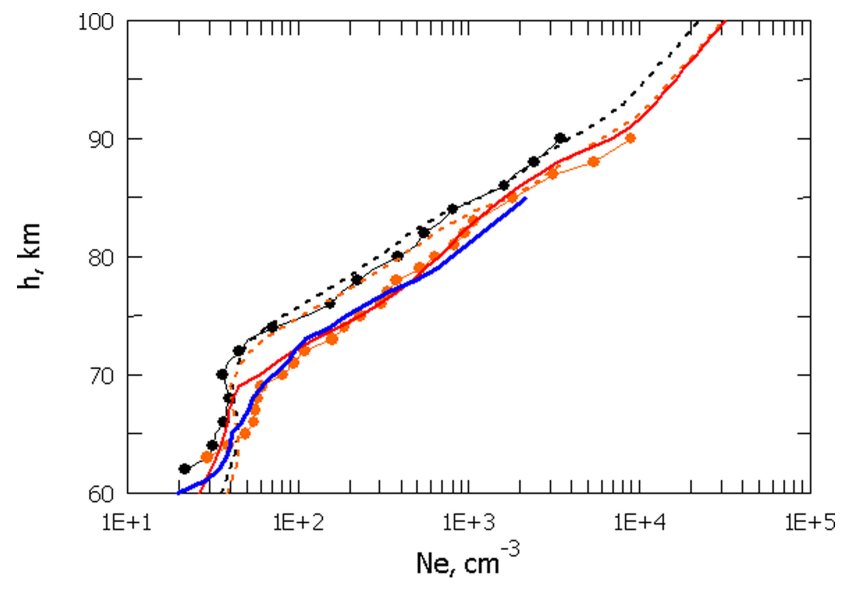

06.08.1986, $X=76, F(10.7)=70 \longrightarrow$ Model: $-\ldots . . . N O-1$ $09.08 .1989, X=76, F(10.7)=227 \longrightarrow$ Model: - . - NO- $1-$ NO- 3a 13.06.1990, $X=76, F(10.7)=202$

Fig. 6. Electron density profiles measured at a solar zenith angle of $76^{\circ}$ for low and high solar activity and modeled on the basis of the NO-1 and 3a profiles for the same conditions.

Experimental data demonstrate that, under the same geophysical conditions, electron number density in the lower ionosphere varies on a day-to-day basis. Differences between summer $N_{\mathrm{e}}$ values can reach about a factor 2 . The model is able to explain such deviations at altitudes between 70 and $90 \mathrm{~km}$ by variations of NO concentration which are limited by the NO-1 and the NO-1d profiles (Solomon et al., 1982).

Electron density profiles measured after noon, at solar zenith angle $76^{\circ}$, but for different solar activity 

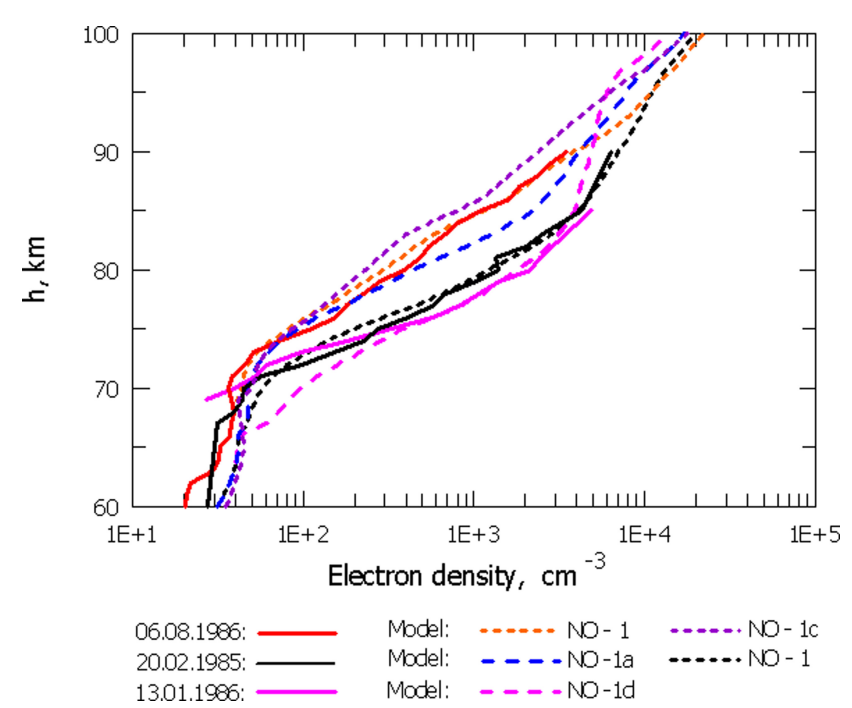

Fig. 7. Electron number density profiles measured in summer (6 August 1986 , solar zenith angle $76^{\circ}, F_{10.7}=70$ ) and in winter (20 February 1985 and 13 January 1986, solar zenith angle $76^{\circ}$, $F_{10.7}=70$ and 76.8). Electron densities modeled on the basis of the $\mathrm{H}_{2} \mathrm{O}-\mathrm{s} 1$ (summer), $\mathrm{H}_{2} \mathrm{O}-\mathrm{w} 1$ (winter) and NO-1a, 1, 1c and $1 \mathrm{~d}$ profiles (dashed lines).

(6 August 1986, $F_{10.7}=70$; 9 August 1989, $F_{10.7}=227$; 13 June $1990, F_{10.7}=202$ ) are shown in Fig. 6 with solid black, red and blue lines. Electron number densities differ from each other. For minimum and maximum activity, the difference between $N_{\mathrm{e}}$ values at altitudes $68-82 \mathrm{~km}$ is about a factor 2. Samples of modeled $N_{\mathrm{e}}$ profiles calculated for corresponding conditions on the basis of the daytime NO-1 profile are shown with short dashed black (low activity) and short dashed red (high activity) lines. For low solar activity, the modeled and experimental $N_{\mathrm{e}}$ profiles are in rather good agreement. The maximum deviations between them, of a factor of 1.4-1.3, are seen at altitudes between 75 and $82 \mathrm{~km}$. In order to reproduce experimental data between 70 and $80 \mathrm{~km}$ during high solar activity, higher NO concentrations between 70 and $80 \mathrm{~km}$ are required than during low solar activity, in agreement with both theoretical models of NO (e.g. Shimazaki and Laird, 1972) and experimental data (HALOE).

Figure 7 shows how experimental and modeled electron density profiles respond to season changes. The electron density profiles have been measured after noon, under similar geophysical conditions but in different season, i.e. in summer (6 August $\left.1986, \chi=76^{\circ}, F_{10.7}=70\right)$ and in winter (20 February $1985, \chi=76^{\circ}, F_{10.7}=76.7$ and 13 January $1986, \chi=76^{\circ}, F_{10.7}=76.8$ ). Seasonal differences in the electron density are rather pronounced. Electron density measured on 20 February 1985 exceeds summer values by a factor of 2.4 at $75 \mathrm{~km}$ and by a factor of 3.6 at $80 \mathrm{~km}$. For both days, modeled electron density profiles have been calculated for all NO profiles represented in Fig. 1a. For the summer ionosphere the water vapor profile $\mathrm{H}_{2} \mathrm{O}$-s1 measured in sum-

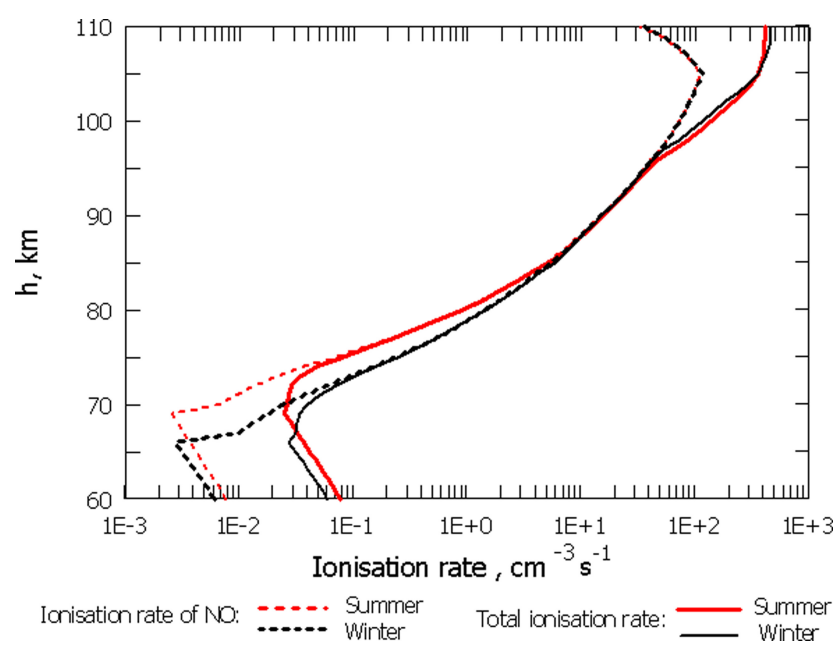

Fig. 8. Profiles of the ionization rate of nitric oxide by Ly- $\alpha$ emission (dashed lines) and total ionization rate for 6 August 1986 and 20 February 1985 (solid lines) on the basis of NO-1 profile.

mer is used; for the winter ionosphere - the $\mathrm{H}_{2} \mathrm{O}$-w1 profile. In the both cases, the best agreement between modeled and experimental data is obtained for the NO-1 profile.

In Fig. 8 quantitative estimations of the ionization rates calculated for summer and winter on the basis of the NO1 profile are shown. Ionization rate profiles coincide at altitudes above $80 \mathrm{~km}$ and have small differences below $80 \mathrm{~km}$. It is evident that ionization rates are not the reason for the large discrepancy between summer and winter modeled $N_{\mathrm{e}}$ profiles. The model describes seasonal differences in experimental values of electron density via meteorological factors. The efficiencies of the hydration chains of $\mathrm{NO}^{+}$and $\mathrm{O}_{2}^{+}$using water vapor profiles $\mathrm{H}_{2} \mathrm{O}$-s 1 and $\mathrm{H}_{2} \mathrm{O}$-w 1 are shown in Fig. 9a and $\mathrm{b}$. In winter the efficiency of both hydration channels, $B\left(\mathrm{NO}^{+}\right)$and $B\left(\mathrm{O}_{2}^{+}\right)$, is significantly less than in summer. Because of the increase of mesospheric temperature in winter (the MSIS model gives $\Delta T=15-38 \mathrm{~K}$ in the range $75-90 \mathrm{~km})$, the absolute values of $B\left(\mathrm{O}_{2}^{+}\right)$at altitudes of about $80 \mathrm{~km}$ are 4 times less in winter than in summer. For $B\left(\mathrm{NO}^{+}\right)$ the difference between winter and summer values is up to 13 times. Seasonal variations in the water vapor have additional effects on the efficiencies of cluster formation and the electron number density. The joint effect of seasonal changes in temperature and water vapor leads to an increase of the electron number density by up to 2.4 times at $75 \mathrm{~km}$ and up to 4 times at $80 \mathrm{~km}$ during winter, i.e. to the same seasonal differences in the model values of electron density which are observed in experimental data. Seasonal variations of effective recombination coefficient are shown in Fig. 10 (black and red solid curves).

The electron density measured on 13 January 1986 exceeds the summer $N_{\mathrm{e}}$ values by a factor of 2.9 at $75 \mathrm{~km}$ and of $5.5 \mathrm{at} 80 \mathrm{~km}$. The model is not able to describe such large differences in electron density by regular seasonal changes 


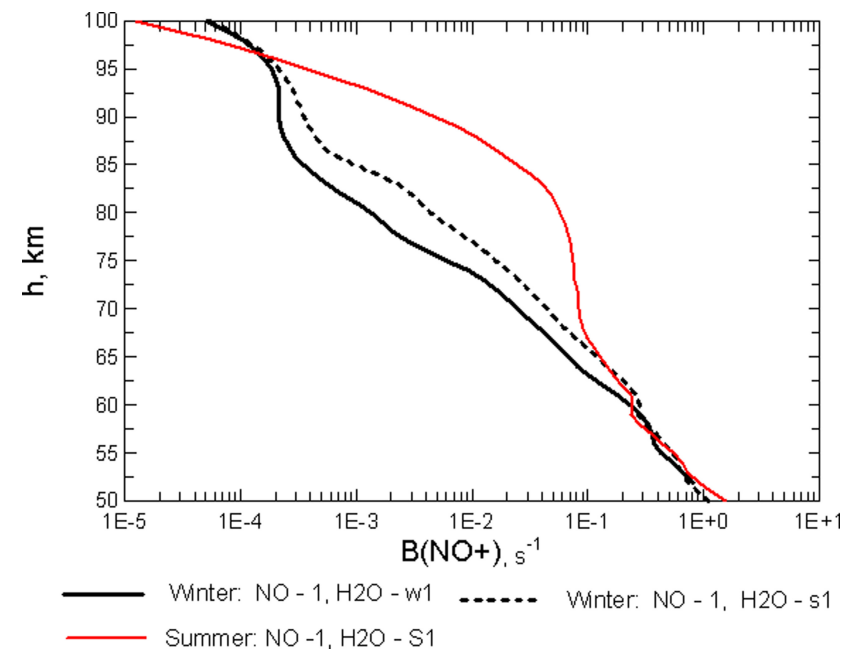

Fig. 9a. Efficiency of the hydration chain of $\mathrm{NO}^{+}$in summer (red line) and winter (black solid and dashed lines). Calculations are made on the basis of NO-1 profile.

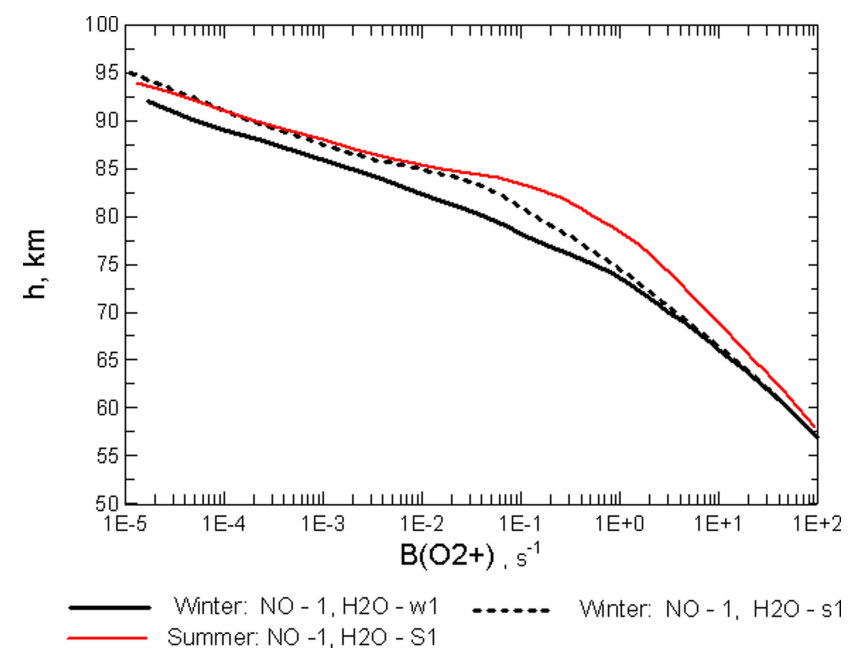

Fig. 9b. Efficiency of the hydration chain of $\mathrm{O}_{2}^{+}$in summer (red solid line) and winter (black lines).

of the water vapor concentration and the neutral atmosphere temperature. In such cases higher concentrations of nitric oxide are required in order to produce additional electron density.

Figure 11 demonstrates variability in electron number density from day to day in the winter ionosphere. It is much more pronounced than in summer (Fig. 5a). The model calculations show that it might be caused by variations of $\mathrm{NO}$ concentration ( 3 solid curves in Fig. 11). It should be noted that, in winter, the required concentrations of NO lie inside a wider range of values, between the NO profiles 1a and 1d, compared to summer NO concentrations. On the other hand, it is known that, apart from regular seasonal changes of the neutral atmosphere temperature, the mesosphere is also

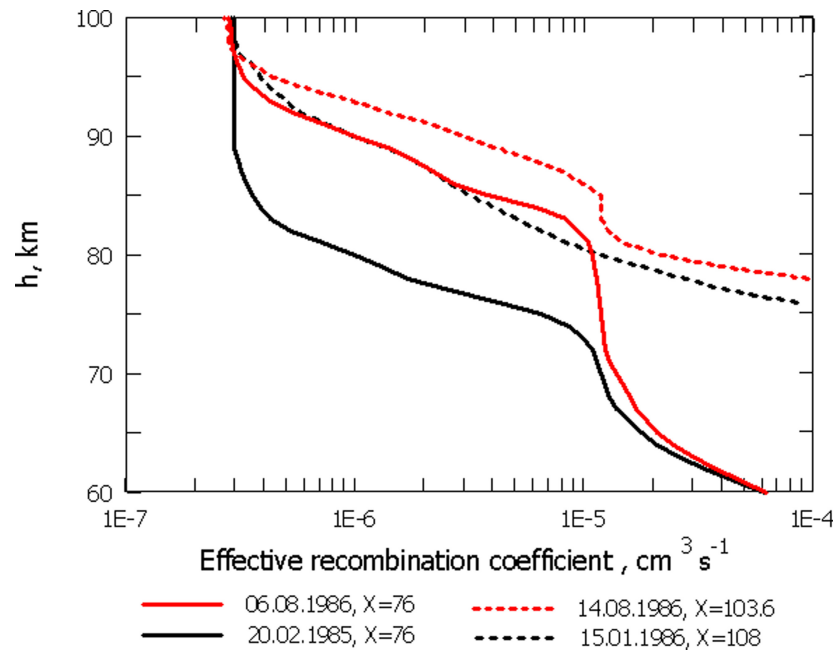

Fig. 10. Height profiles of the effective recombination coefficient calculated for summer, 6 August 1986 (red lines), and for winter, 20 February 1985 (back lines), at solar zenith angles $76^{\circ}$ (solid lines) and larger than $100^{\circ}$ (dashed lines).

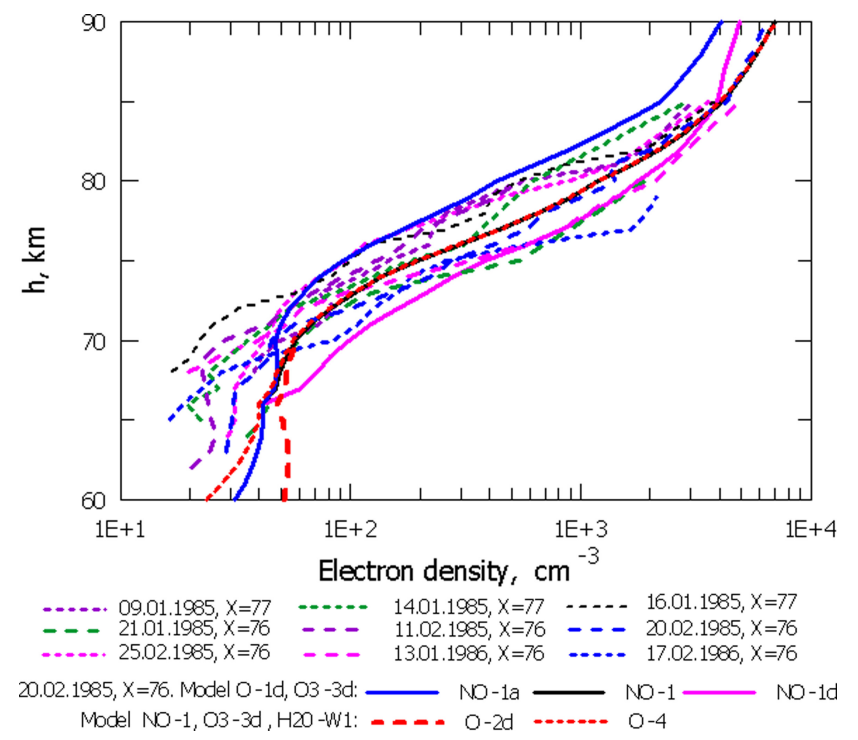

Fig. 11. Electron number density profiles measured in winter at solar zenith angles $76-77^{\circ}, F_{10.7}=67-85$ (dashed lines). Electron density profiles modeled for 20 February 1985 on the basis of the NO-1a, 1 and 1d profiles (solid lines).

characterized by temperature variations during each season, due to gravity and planetary waves, atmospheric tides and other factors (Hauchecorne et al., 1987; Aikin et al., 1991; Yu et al., 1997; States and Gardner, 1998; Shepherd et al., 2001). Significant (up to $\pm 30 \mathrm{~K}$ ) and irregular temperature fluctuations are observed often especially in the winter mesosphere (Theon et al., 1967; Shepherd et al., 2001). This phenomenon is known as the winter anomaly (Aikin et al., 1977; Offermann, 1979). They might also be responsible for large 
variability of electron number density on winter days. Since individual temperature profiles can significantly differ from the mean temperature profiles provided by the MSIS model, the role of each factor (NO or $\Delta T$ ) in formation of $N_{\mathrm{e}}$ profiles in the daytime winter ionosphere can be understood only by detailed studies using real temperature profiles of the winter mesosphere. Influence of atomic oxygen concentration on the electron number density in the winter ionosphere is shown by two dashed red lines.

Figure 12 shows electron density profiles measured in the winter ionosphere at solar zenith angles in the range of 100 $110^{\circ}$ during low solar activity. Calculations of the modeled electron density profiles have been made on 15 January 1986, $\left(\chi=108^{\circ}, F_{10.7}=77.7\right)$, using different night profiles of atomic oxygen, ozone and nitric oxide. The modeled profile that is very close to the experimental values has been obtained on the basis of the O-1n, $\mathrm{O}_{3}-3 \mathrm{n}$ and NO-2 profiles. This modeled $N_{\mathrm{e}}(h)$ profile and the $N_{\mathrm{e}}(h)$ profile calculated for 14 August 1986 at $\chi=103.6^{\circ}$ (Fig. 4), have been used to determine the effective recombination coefficients at nighttime in the winter and summer ionosphere (black and red dashed curves in Fig. 10). It can be seen, that the model provides strong dependence of effective recombination coefficient on both season and solar zenith angle.

\section{Discussion and conclusion}

Modeled ionization rates and electron number density, based on different profiles of minor neutral constituents $\left(\mathrm{NO}, \mathrm{H}_{2} \mathrm{O}\right.$, $\mathrm{O}$ and $\mathrm{O}_{3}$ ), covering a broad range of values, have been presented in this study. Correct estimation of the role of the nitric oxide concentration in formation of the electron density profile depends, first of all, on accurate calculations of the ionization rate. In Fig. $5 b$ the ionization rates provided by different solar sources at zenith angles $44.6^{\circ}$ and $76^{\circ}$; moreover, cosmic rays are shown. The model calculations confirm that $\mathrm{NO}$ molecules ionized by $\mathrm{Ly}-\alpha$ emission are the major source of electrons and positive ions in the quiet sunlit D-region. The height interval where the ionization rate produced by Ly- $\alpha$ is dominant depends on both the NO concentration (Fig. 3b) and solar zenith angle (Fig. 5b). Near noon $\left(\chi=44.6^{\circ}\right)$, the contribution of the Ly- $\alpha$ emission to the electron production rate is the largest between 68 and $85 \mathrm{~km}$. Calculations using a wide spectrum of NO concentrations as model input, from minimum (the NO-1a profile) to maximum (the NO-profile $1 \mathrm{~d}$ or $3 \mathrm{a}$ ) values, demonstrate that the difference between the minimum and maximum values of the ionization rate at $68-85 \mathrm{~km}$ might be up to a factor 10 (Fig. 3b). Differences between the maximum and minimum values in the electron number density caused by NO variations are of the order of 2.8-3.5 times (Fig. 3a). When the solar zenith angle increases $\left(\chi=76^{\circ}\right)$ and the contribution of the Ly- $\alpha$ emission to the electron production rate becomes significant over a wider height range (Fig. 5b), the influence

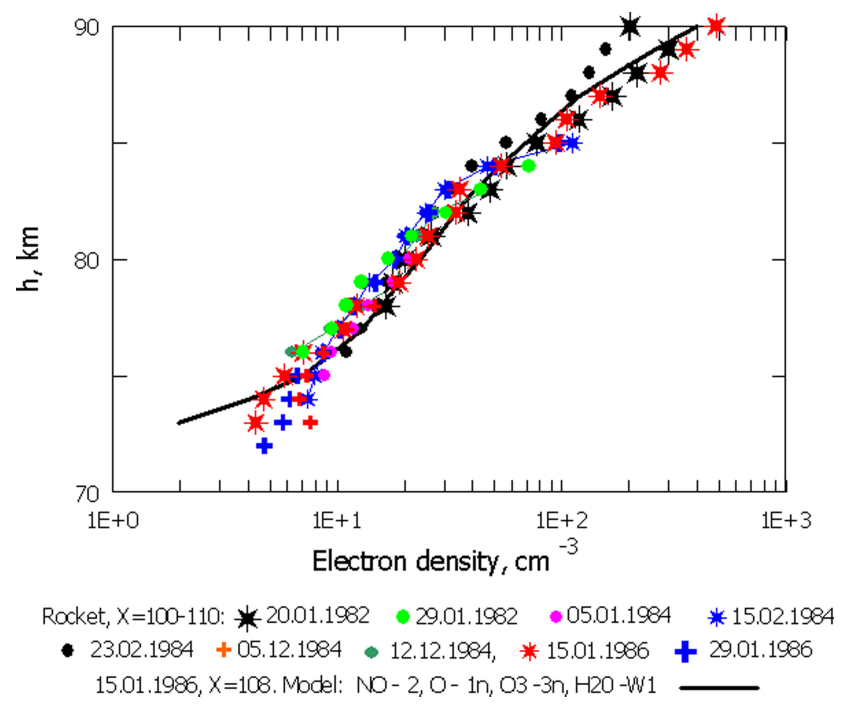

Fig. 12. Electron number density profiles measured in winter at solar zenith angles $100^{\circ}-110^{\circ}, F_{10.7}=67-85$ (lines with symbols). Electron density modeled for 15 January 1986 at solar zenith angle $108^{\circ}, F_{10.7}=77.7$ (black solid line).

of NO concentration on electron number density extends to 100 km (Fig. 5a).

It has been demonstrated that if water vapor concentration at all altitudes of the mesosphere decreases by more than a factor 2, significant increase of electron number density takes place only in the height interval between 73 and $85 \mathrm{~km}$ and then only if the water concentration at these altitudes changes by more than a factor 5 . In the sunlit ionosphere, influence of atomic oxygen and ozone concentrations on electron density is seen only at altitudes below $70 \mathrm{~km}$. A change in the atomic oxygen concentration at 65 and $60 \mathrm{~km}$ by a factor of 10 leads to changes in the electron density by a factor of 1.5 and 2.3 , respectively. The effect of the change of ozone concentration is less significant. The model describes this altitudedependent response of electron density to changes of water, atomic oxygen and oxygen in the frame of the ion-chemical model through the participation of these species in the ionmolecular reactions.

Comparison between experimental and model electron density profiles, calculated in each individual case under the same conditions (date, time, latitude, longitude, $\chi, F_{10.7}$ ), demonstrates that the model is able to reproduce the electron density profiles in the quiet summer and winter ionosphere on the basis of NO profiles which are inside the range of available NO values. On summer days, during low solar activity, the profile NO-1 provides coincidence between model and experimental data for most of the cases considered. In order to keep agreement between the modeled and measured electron density profiles during high solar activity $\left(F_{10.7}=200-220\right)$ the number density of nitric oxide below $80 \mathrm{~km}$ should be higher than during low $\left(F_{10.7}=70\right)$ activity 
by 3-4 times (Fig. 6). This corresponds to both statistical data on NO concentration in the upper mesosphere obtained from the satellite measurements for different levels of the solar activity and the conclusions deduced from diffusion photochemical models. The model calculation shows that deviations (by a factor 2) in experimental summer $N_{\mathrm{e}}$ values at altitudes $70-90 \mathrm{~km}$ can be stipulated by changes of NO concentration which are limited by the NO- 1 and the NO-1d profiles.

Large variability in experimental winter $N_{\mathrm{e}}$ values can be caused both by strong variability of NO concentration and strong fluctuations of the temperature in the winter mesosphere. Available NO profiles (between the NO-1a and the NO-1d) might explain deviations in experimental values of electron density above $70 \mathrm{~km}$ (Fig. 11). On other hand, because of the strong inverse dependence of the $\mathrm{NO}^{+}$hydration channel efficiency on temperature, frequent and large temperature oscillations in the winter mesosphere might be also responsible for observed deviations in electron density. The real temperature profiles can significantly differ from the MSIS profiles, especially in the region of the mesopause. Positive fluctuations of temperature decrease the cluster ions formation rate and effective recombination coefficient, and the electron density can increase by several times, depending on the altitude, compared to an average winter day, and vice versa. In order to understand the role of each factor (NO or $\Delta T$ ) in formation of the $N_{\mathrm{e}}$ profile, it is necessary to incorporate the real temperature profiles into the model. In this case the possibility appears to determine which height profiles of nitric oxide are the most appropriate for the mesosphere on winter days.

Due to realistic assumptions concerning the dependence of the main cluster ions formation processes on temperature, the model is able to explain regular seasonal variations in the electron number density and effective recombination coefficient (Figs. 7 and 10) in terms of temperature and water vapor seasonal variations.

The theoretical model for quiet lower ionosphere has been applied to compute ionization rate and electron density profiles in the summer and winter D-region. In order to minimize possible errors in estimation of ionization rates by solar electromagnetic radiation and obtain the best values of electron density, each wavelength range of the solar spectrum has been divided into several intervals and the relation between the solar radiation intensity at these wavelengths and the solar activity index $F_{10.7}$, deduced by Nusinov (1992), has been implemented. The lack of reliable data on the height distribution of minor neutral constituents in the mesosphere is also a problem for reasonable estimation of the ionospheric parameters in the quiet ionosphere. In this study we have examined the influence of minor neutral species concentration on the ionization balance at different altitudes of the D-region and the response of the modeled $N_{\mathrm{e}}(h)$ profiles to changes in solar zenith angle, solar activity and season. Calculations have been made at solar zenith angles less than $80^{\circ}$ and more than $99^{\circ}$, under steady state conditions. Modeled electron density profiles have been evaluated by comparison with experimental profiles available from the rocket measurements made in Volgograd region $\left(48.5^{\circ} \mathrm{N}, 45.6^{\circ} \mathrm{E}\right)$.

We have shown that our theoretical model for the quiet lower ionosphere is quite effective in describing variations in ionization rate, effective recombination coefficient and electron number density as functions of solar zenith angle, solar activity and season (for $T$ and $\mathrm{H}_{2} \mathrm{O}$ ). The profiles O-1d or O$2 \mathrm{~d}$, and $\mathrm{O}_{3}-3 \mathrm{~d}$ (Fig. 2a) can be used to model electron density in the sunlit ionosphere. The profiles $\mathrm{H}_{2} \mathrm{O}-\mathrm{s} 1$, s2, and $\mathrm{H}_{2} \mathrm{O}-$ w1 (Fig. 2b) are suitable for modeling in the summer and winter ionosphere, respectively. The NO-1 profile (Solomon et al., 1982) gives the best values of electron density in the daytime summer ionosphere during low solar activity and the NO profiles with higher NO concentrations give the best values during high solar activity. For modeling in the daytime winter ionosphere the range of applied NO profiles is rather wide. The modeling of the ionospheric parameters on winter days is less successful than for summer conditions.

The results presented in this study are based on a theoretical model for the lower ionosphere which is relatively simple compared to the models on a planetary scale which include several hundred chemical reactions, dozens of ions, electrodynamics of plasma, neutral constituents chemistry, plasma and neutral wind dynamics, optics and etc. (Kull et al., 1997; Verronen et al., 2002; Kazil et al., 2003; Enell et al., 2011). The complex models are extremely important for detailed research of ionosphere and magnetosphere physics. Along with their undeniable merits, they have also intrinsic limitations. First of all, the limitations may be associated with inadequacies in the reaction rate constants and the uncertainties of some chemical reaction paths included in the detailed ion and neutral chemical schemes. One of the goals for construction of the "simple" models is to avoid such problems by means of reasonable simplification of the ion-molecular processes scheme. In addition, the complete and simple models may fulfill different tasks. For example, the simple model having incorporated the appropriate minor neutral constituents profiles ( $\mathrm{NO}, \mathrm{O}, \mathrm{O}_{3}, \mathrm{H}_{2} \mathrm{O}, \mathrm{O}_{2}\left(1 \Delta_{\mathrm{g}}\right), \mathrm{NO}_{2}, \mathrm{CO}_{2}$ ) will allow more accurate modeling of electron and ion densities in a given geophysical situation, without the need to apply complete model calculations of all neutral species. In addition, the simple model may be applied to solve the inverse tasks. It may provide the kernel for spectra recovering methods and techniques, for example, deducing flux-energy spectrum of electrons precipitating into the polar ionosphere from groundbased or rocket measurements of electron density profile (Osepian and Kirkwood, 1996; Osepian and Smirnova, 1997). The model can be used for estimations of minor neutral species concentration in the mesosphere under quiet or disturbed conditions on basis of available experimental electron density profiles. This type of model can provide the quick information needed for calculation and forecasting of radio waves propagation in a wide range of frequencies in various 
Table A1. Rate constants for the positive ion reactions, $\mathrm{cm}^{3} \mathrm{~s}^{-1}$ (Smirnova et al., 1988).

\begin{tabular}{cccc}
\hline$r_{1}$ & $1.8 \times 10^{-28}(300 / T)^{4.7}$ & $K_{2}$ & $3.0 \times 10^{-10}$ \\
$r_{2}$ & $2.0 \times 10^{-31}(300 / T)^{4.4}$ & $K_{3}$ & $1.0 \times 10^{-10}$ \\
$r_{-2}$ & $1.5 \times 10^{6} T^{-5.4} \mathrm{exp}(-2450 / T)$ & $K_{4}$ & $2.2 \times 10^{-9}$ \\
$r_{3}$ & $1.0 \times 10^{-9}$ & $k_{5}$ & $4.4 \times 10^{-10}$ \\
$r_{4}$ & $1.0 \times 10^{-9}$ & $k_{6}$ & $1.0 \times 10^{-17}$ \\
$r_{5}$ & $7.0 \times 10^{-30}(300 / T)^{3}$ & $v_{1}$ & $8.0 \times 10^{-31}(300 / T)^{4.4}$ \\
$r_{-5}$ & $3.1 \times 10^{4} T^{-4} \mathrm{exp}(-4590 / T)$ & $\alpha\left(\mathrm{O}_{2}^{+}\right)$ & $2.0 \times 10^{-7}(300 / T)$ \\
$r_{6}$ & $1.0 \times 10^{-9}$ & $\alpha\left(\mathrm{NO}^{+}\right)$ & $4.0 \times 10^{-7}(300 / T)$ \\
$r_{7}$ & $1.0 \times 10^{-27}(300 / T)^{4.4}$ & $\alpha\left(\mathrm{Cl}_{1}^{+}\right)$ & $2.0 \times 10^{-6}$ \\
$K_{1}$ & $2.4 \times 10^{-30}(300 / T)^{3.2}$ & $\alpha\left(\mathrm{Cl}_{2}^{+}\right)$ & $1.0 \times 10^{-5}$ \\
$K_{-1}$ & $1.8 \times 10^{-5}(300 / T)^{4.2} \exp (-5600 / T)$ & & \\
\hline
\end{tabular}

Table A2. Rate constants for the negative ion reactions, $\mathrm{cm}^{3} \mathrm{~s}^{-1}$ (Smirnova et al., 1988).

\begin{tabular}{cccc}
\hline$\beta_{1}$ & $1.4 \times 10^{-29}(300 / T) . \exp (-600 / T)$ & $\beta_{12}$ & $4.0 \times 10^{-31}(300 / T)^{5}$ \\
$\beta_{2}$ & $1.0 \times 10^{-31}$ & $\beta_{13}$ & $2.0 \times 10^{-29}(300 / T)^{5}$ \\
$\beta_{3}$ & $1.5 \times 10^{-10}$ & $\beta_{14}$ & $6.0 \times 10^{-10}$ \\
$\beta_{4}$ & $2.0 \cdot 10^{-10}$ & $\beta_{15}$ & $9.0 \times 10^{-31}(300 / T)^{5}$ \\
$\beta_{5}$ & $9.1 \times 10^{-12}(300 / T)^{-1.46}$ & $\beta_{16}$ & $3.1 \times 10^{-28}(300 / T)^{5}$ \\
$\beta_{6}$ & $1.9 \times 10^{-10}$ & $\beta_{17}$ & $5.3 \times 10^{-10}$ \\
$\beta_{7}$ & $2.0 \times 10^{-10}$ & $\rho_{1}$ & 0.33 \\
$\beta_{8}$ & $1.1 \times 10^{-10}$ & $\rho_{2}$ & 1.4 \\
$\beta_{9}$ & 0.15 & $\rho_{3}$ & $1.5 \times 10^{-3}$ \\
$\beta_{10}$ & $1.1 \times 10^{-11}$ & $\alpha_{i}$ & $6.8 \cdot T^{-0.4}$ \\
$\beta_{11}$ & $2.0 \times 10^{-10}$ & & \\
\hline
\end{tabular}

geophysical conditions, i.e. they can be used for any certain practical purpose.

\section{Appendix A}

\section{Ion chemistry model}

A block diagram of the ion-chemical model of the D-region is illustrated by Smirnova et al. (1988) in Fig. 1. Equations for computing reaction rates for positive and negative ions are given below:

$$
\begin{aligned}
d\left[\mathrm{O}_{2}^{+}\right] / d t= & Q\left(\mathrm{O}_{2}^{+}\right)-\left(k_{5}[\mathrm{NO}]+k_{6}\left[\mathrm{~N}_{2}\right]+B\left(\mathrm{O}_{2}^{+}\right)\right. \\
+ & \left.\alpha\left(\mathrm{O}_{2}^{+}\right) \cdot N_{\mathrm{e}}+\alpha_{\mathrm{i}} \cdot \mathrm{N}^{-}\right) \cdot\left[\mathrm{O}_{2}^{+}\right] \\
d\left[\mathrm{NO}^{+}\right] / d t= & Q\left(\mathrm{NO}^{+}\right)+\left(k_{5}[\mathrm{NO}]+k_{6}\left[\mathrm{~N}_{2}\right]\right) \cdot\left[\mathrm{O}_{2}^{+}\right] \\
& -\left(B\left(\mathrm{NO}^{+}\right)+\alpha\left(\mathrm{NO}^{+}\right) \cdot N_{\mathrm{e}}+\alpha_{\mathrm{i}} \cdot \mathrm{N}^{-}\right) \cdot\left[\mathrm{NO}^{+}\right] \\
d\left[\mathrm{Cl}_{1}^{+}\right] / d t= & B\left(\mathrm{O}_{2}^{+}\right) \cdot\left[\mathrm{O}_{2}^{+}\right]+B\left(\mathrm{NO}^{+}\right) \cdot\left[\mathrm{NO}^{+}\right]-\left(r_{7}\left[\mathrm{H}_{2} \mathrm{O}\right]\left[\mathrm{N}_{2}\right]\right. \\
& \left.+\alpha\left(\mathrm{Cl}_{1}^{+}\right) \cdot N_{\mathrm{e}}+\alpha_{\mathrm{i}} \cdot \mathrm{N}^{-}\right) \cdot\left[\mathrm{Cl}_{1}^{+}\right]
\end{aligned}
$$$$
d\left[\mathrm{Cl}_{2}^{+}\right] / d t=r_{7}\left[\mathrm{H}_{2} \mathrm{O}\right]\left[\mathrm{N}_{2}\right]\left[\mathrm{Cl}_{1}^{+}\right]-\left(\alpha\left(\mathrm{Cl}_{2}^{+}\right) \cdot N_{\mathrm{e}}+\alpha_{\mathrm{i}} \cdot \mathrm{N}^{-}\right) \cdot\left[\mathrm{Cl}_{2}^{+}\right]
$$

$$
\begin{aligned}
d\left[\mathrm{O}_{2}^{-}\right] / d t= & \left(\beta_{1}\left[\mathrm{O}_{2}\right]^{2}+\beta_{2}\left[\mathrm{O}_{2}\right]\left[\mathrm{N}_{2}\right]\right) \cdot N_{\mathrm{e}}+\beta_{8}[\mathrm{O}]\left[\mathrm{CO}_{3}^{-}\right] \\
& -\left(B\left(\mathrm{O}_{2}^{-}\right)+2 \beta_{3}[\mathrm{O}]+\beta_{4}\left[\mathrm{O}_{2}\left({ }^{1} \Delta_{\mathrm{g}}\right)\right]\right. \\
& \left.+\rho_{1}+\alpha_{\mathrm{i}} \cdot \mathrm{N}^{+}\right) \cdot\left[\mathrm{O}_{2}^{-}\right] \\
d\left[\mathrm{O}^{-}\right] / d t=\beta_{5}\left[\mathrm{O}_{3}\right] \cdot \mathrm{Ne}+\beta_{3}[\mathrm{O}]\left[\mathrm{O}_{2}^{-}\right]+\beta_{9}\left[\mathrm{CO}_{3}^{-}\right]-\left(\beta_{6}[\mathrm{O}]\right. & \left.+\beta_{7}\left[\mathrm{O}_{2}\left({ }^{1} \Delta_{\mathrm{g}}\right)\right]+\rho_{2}+B\left(\mathrm{O}^{-}\right)+\alpha_{\mathrm{i}} \cdot \mathrm{N}^{+}\right) \cdot\left[\mathrm{O}^{-}\right] \\
d\left[\mathrm{CO}_{3}^{-}\right] / d t= & B\left(\mathrm{O}_{2}^{-}\right) \cdot\left[\mathrm{O}_{2}^{-}\right]+B\left(\mathrm{O}^{-}\right) \cdot\left[\mathrm{O}^{-}\right]-\left(\beta_{8}[\mathrm{O}]+\beta_{9}\right. \\
& \left.+\beta_{10}[\mathrm{NO}]+\beta_{11}\left[\mathrm{NO}_{2}\right]+\alpha_{\mathrm{i}} \cdot \mathrm{N}^{+}\right) \cdot\left[\mathrm{CO}_{3}^{-}\right] \\
d\left[\mathrm{NO}_{3}^{-}\right] / d t= & \left(\beta_{10}[\mathrm{NO}]+\beta_{11}\left[\mathrm{NO}_{2}\right]\right) \cdot\left[\mathrm{CO}_{3}^{-}\right] \\
& -\left(\rho_{3}+\alpha_{\mathrm{i}} \cdot \mathrm{N}^{+}\right) \cdot\left[\mathrm{NO}_{3}^{-}\right]
\end{aligned}
$$

The efficiency $B\left(\mathrm{NO}^{+}\right)$of the channel $\mathrm{NO}^{+} \rightarrow \mathrm{NO}^{+} \cdot\left(\mathrm{H}_{2} \mathrm{O}\right)$ is given by the following expression:

$$
\begin{aligned}
B\left(\mathrm{NO}^{+}\right)= & {\left[\mathrm{H}_{2} \mathrm{O}\right]\left(r_{1}\left[\mathrm{~N}_{2}\right]+\frac{r_{2}\left[\mathrm{~N}_{2}\right]^{2} r_{4}}{c}+\frac{r_{6}}{r_{6}\left[\mathrm{H}_{2} \mathrm{O}\right] r_{-5}\left[\mathrm{~N}_{2}\right]}\right.} \\
& \left.\left(r_{5}\left[\mathrm{CP}_{2}\right]\left[\mathrm{N}_{2}\right]+\frac{r_{2}\left[\mathrm{~N}_{2}\right]^{2} r_{5}\left[\mathrm{CO}_{2}\right]}{c}\right)\right)
\end{aligned}
$$

where $c=r_{-2}\left[\mathrm{~N}_{2}\right]+r_{3}\left[\mathrm{CO}_{2}\right]+r_{4}\left[\mathrm{H}_{2} \mathrm{O}\right]$. Reaction rate constants $r_{1}, r_{2}, r_{-2}, r_{5}$ and $r_{-5}$ depend on temperature and are given in Table A1.

The efficiency $\mathrm{B}\left(\mathrm{O}^{2+}\right)$ of the channel $\mathrm{O}_{2}^{+} \rightarrow \mathrm{O}_{2}^{+} \cdot\left(\mathrm{H}_{2} \mathrm{O}\right)$ is

$$
B\left(\mathrm{O}_{2}^{+}\right)=\frac{K_{1}\left[\mathrm{O}_{2}\right]^{2}+v_{1}\left[\mathrm{~N}_{2}\right]^{2}}{\frac{K_{2}[\mathrm{O}]+K_{3}\left[\mathrm{O}_{2}(1 \Delta g)\right]+K_{-1}\left[\mathrm{O}_{2}\right]}{K_{4}\left[\mathrm{H}_{2} \mathrm{O}\right]}+1}
$$

where $K_{1}, K_{-1}, K_{2}, K_{3}$, and $K_{4}$ are the reaction rate constants given in Table A1. The constants $K_{1}, K_{-1}$ and $v_{1}$ depend on temperature.

Efficiencies of the channels $\mathrm{O}_{2}^{-} \rightarrow \mathrm{O}_{3}^{-}, \mathrm{O}_{4}^{-}, \mathrm{CO}_{4}^{-} \rightarrow \mathrm{CO}_{3}^{-}$ and $\mathrm{O}^{-} \rightarrow \mathrm{O}_{3}^{-} \rightarrow \mathrm{CO}_{3}^{-}$are given by the expressions:

$B\left(\mathrm{O}_{2}^{-}\right)=\beta_{12}\left[\mathrm{O}_{2}\right]^{2}+\beta_{13}\left[\mathrm{O}_{2}\right]\left[\mathrm{CO}_{2}\right]+\beta_{14}\left[\mathrm{O}_{3}\right]$ 
$B\left(\mathrm{O}^{-}\right)=\beta_{15}\left[\mathrm{O}_{2}\right]^{2}+\beta_{16}\left[\mathrm{O}_{2}\right]\left[\mathrm{CO}_{2}\right]+\beta_{17}\left[\mathrm{O}_{3}\right]$

where $\beta_{12-17}$ are rate constants given in Table A2.

Proton hydrates $\mathrm{H}^{+} \cdot\left(\mathrm{H}_{2} \mathrm{O}\right)_{n}$ are formed from $\mathrm{Cl}_{1}^{+}$with rate $\beta$ according to

$$
\beta=10^{-27} \cdot(300 / T)^{4.4}\left[\mathrm{H}_{2} \mathrm{O}\right]\left[\mathrm{N}_{2}\right]\left[\mathrm{Cl}_{1}^{+}\right]
$$

Acknowledgements. The authors thank The Education, Audiovisual and Culture Executive Agency (EACEA) for support of this work within the frame of the Erasmus Mundus Master Course in Space Science and Technology - SpaceMaster, 2009-2013. The authors thank M. Friedrich and the second referee for their valuable comments and suggestions.

Editor-in-chief M. Pinnock and Topical Editor P.-L. Blelly thank M. Friedrich and one anonymous referee for their help in evaluating this paper.

\section{References}

Aikin, A. C., Goldberg, R. A., Jones. W., and Kane, J. A.: Observations of the mid-latitude lower ionosphere in winter, J. Geophys. Res., 82, 1869-1875, 1977.

Aikin, A. C., Chanin, M. L., Nash, J., and Kendig, D. J.: Temperature trends in the lower mesosphere, J. Geopys. Res. Lett., 18, 416-419, 1991.

Brasseur, G. and Offermann, D.: Recombination of atomic oxygen near the mesopause: Interpretation of rocket data. J. Geophys. Res., 91, 10818-10824, 1986.

Danilov, A. D.: New ideas on the D-region modeling, Adv. Space Res., 25, 5-14, 2000.

Danilov, A. D. and Ledomskya, S. Y.: Empirical model for D region. Main principles and data base. Physics of the Upper Atmosphere, IEM. Ed 13(102), Moscow, 1983 (in Russian).

DeMore, W. B., Sander, S. P., Golden, D. M, Molina, M. J., Hampson, R. F., Kurolo, M.J, Howard, C. J., and Ravishankara, A. R.: Chemical kinetics and Photochemical Data for Use in Stratospheric Modeling, JPL Publication 90-I, Jet Propulsion Laboratory, California Institute of Technology, Pasadena, USA, 1994.

Enell, C.-F., Hedin, J., Stegman, J., Witt, G., Friedrich, M., Singer, W., Baumgarten, G., Kaifler, B., Hoppe, U.-P., Gustavsson, B., Brändström, U., Khaplanov, M., Kero, A., Ulich, T., and Turunen, E.: The Hotel Payload 2 campaign: Overview of NO, O and electron density measurements in the upper mesosphere and lower thermosphere, J. Atmos. Sol.-Terr. Phys., 73, 2228-2236, 2011.

Friedrich, M. and Torkar, K. M.: An empirical model of the nonauroral D-region, Radio Sci., 27, 945-953, 1992.

Friedrich, M. and Torkar, K. M.: Comparison between an empirical and a theoretical model of the D-region, Adv. Space Res., 21, 895-904, 1998.

Friedrich, M. and Torkar, K. M.: FIRI: A semi-empirical model of the lower ionosphere., J. Geophys. Res., 106, 21409-21418, 2001.
Fussen, D., Vanhellemont, F., and Bingen, C.: Ozone profiles from 30 to $110 \mathrm{~km}$ measured by the Occultation Radiometer instrument during the period Aug. 1992-Apr. 1993. Geophys. Res. Lett., 27, 3449-3452, 2000.

Ginther, J. C. and Smith, L. G.: Studies of the differential absorption. Rocket experiment, Aeronomy Report, 64, Aeron. Lab., 1975.

Grossmann, K. U., Frings, W. G., Offermann, D., Andre, L., Kopp, E., and Krankowsky, D.: Concentrations of $\mathrm{H}_{2} \mathrm{O}$ and $\mathrm{NO}$ in the mesosphere and lower thermosphere at high latitudes, J. Atmos. Terr. Phys., 47, 1-3, 291-300, 1985.

Gumbel, J., Murtagh, D. P., Espy, P. J., Witt, G., and Schmidlin, F. J.: Odd oxygen measurements during the Noctilucent Cloud 93 rocket campaing, J. Geophys. Res-Space Phys., 103, 23399 23414, 1998.

HALOE instrument: http://haloe.gats-inc.com/home/index.php, 2011.

Hauchecorne, A., Shanin, M. L., and Wilson, R.: Mesosphere temperature inversion and gravity wave breaking, Geophys. Res. Lett., 14, 933-936, 1987.

Hedin, A. E.: Extension of the MSIS thermospheric model into the middle and lower atmosphere, J. Geophys. Res., 96, 1159-1172, 1991.

Ivanov-Kholodniy, G. S. and Velichanskiy, V. N.: Research in geomagnetism, aeronomy and solar physics, 26, ed. Nauka, Moscow, 1973 (in Russian).

Kashirin, A. I.: Photoionization in the nighttime ionosphere, Geomagn. Aeronomy, 26, 563-568, 1986 (in Russian).

Kaufmann, M., Gusev, O. A., Grossmann, K. U., MartinTorres, F. J., March, D. R., and Kutepov, A. A.: Satellite observations of daytime and nighttime ozone in the mesosphere and lower thermosphere, J. Geophys. Res., 108, 4272, doi:10.1029/2002JD002800, 2003.

Kazil, J., Kopp, E., Chabrillat, S., and Bishop, J.: The University of Bern Atmospheric Ion Model: Time dependent modeling of the ions in the mesosphere and lower thermosphere, J. Geophys. Res., 18, 4432, doi:10.1029/2002JD003024, 2003.

Keneshea, T. J., Zummermann, S. P., and Philbrick, C. R.: A dynamical model of the mesosphere and lower thermosphere, Planet. Space Sci., 27, 385-401, 1979.

Kirkwood, S.: SPECTRUM - a computer algorithm to derive the flux-energy spectrum of precipitating particles from EISCAT electron density profiles., IRF Tech. Rep. 034, Swedish Institute of Space Physics, 1988.

Kirkwood, S. and Osepian, A.: Quantitative studies of energetic particle precipitation using incoherent scatter radar, J. Geomag. Geoelectr., 47, 783-799, 1995.

Kull, A., Kopp, E., Granier, C., and Brasseur, G.: Ions and electrons of the lower-latitude D-region, J. Geophys. Res., 102, 97059716, 1997.

Marov, M. Y., Shematovich, V. I., and Bisicalo, D. V.: Nonequilibrium aeronomic processes - a kinetic approach to the mathematical modeling, Space Sci. Rev., 76, 1-204, 1996.

McKinnell, L. A. and Friedrich, M.: A neutral network based ionospheric model for the auroral zone, J. Atmos. Solar Terr. Phys., 69, 1459-1470, 2007.

Meira, L. G.: Rocket measurements of upper atmospheric nitric oxide and their consequences to the lower ionosphere, J. Geophys. Res., 76, 202-212, 1971. 
Murray, B. J. and Plane, J. M. C.: Modelling the impact of noctilucent cloud formation on atomic oxygen and other minor constituents of the summer mesosphere, Atmos. Chem. Phys., 5, 1027-1038, doi:10.5194/acp-5-1027-2005, 2005.

Nicolet, M. and Aikin, A. C.: The formation D-region of the ionosphere, J. Geophys. Res., 65, 1469-1483, 1960.

Nusinov, A. A.: Solar X-ray spectrum $0.1-10 \mathrm{~nm}$ at different activity levels, Solar Data, 7, 57-58, 1986.

Nusinov, A. A.: Models for prediction of EUV- and X-ray solar radiation based on $10.7 \mathrm{~cm}$ radio emission, Proceedings of the Workshop on the Solar Electromagnetic Radiation Study for Solar Cycle 22, Boulder, Colorado, 354-359, 1992.

Offermann, D.: Recent advances in the study of the D-region winter anomaly, J. Atmos. Terr. Phys., 41, 735-752, 1979.

Ogawa, T. and Shimazaki, T.: Diurnal variations of odd nitrogen and ionic densities in the mesosphere and lower thermosphere: simultaneous solution of photochemical-diffusive equations, J. Geophys. Res., 80, 3945-3960, 1975.

Osepian, A. and Kirkwood, S.: High-energy electron fluxes derived from EISCAT electron density profiles, J. Atmos. Terr. Phys., 58, 479-487, 1996.

Osepian, A. and Smirnova, N.: Modeling of absorption layer during absorption events, J. Atmos. Sol. Terr. Phys., 59, 951-960, 1997.

Osepian, A., Tereschenko, V., Dalin, P., and Kirkwood, S.: The role of atomic oxygen concentration in the ionization balance of the lower ionosphere during solar proton events, Ann. Geophys., 26, 131-143, doi:10.5194/angeo-26-131-2008, 2008.

Osepian, A., Kirkwood, S., and Dalin, P.: The influence of ozone concentration on the lower ionosphere - modelling and measurements during the 29-30 October 2003 solar proton event, Ann. Geophys., 27, 577-589, doi:10.5194/angeo-27-577-2009, 2009a.

Osepian, A., Kirkwood, S., Dalin, P., and Tereschenko, V.: D-region electron density and effective recombination coefficients during twilight - experimental data and modelling during solar proton events, Ann. Geophys., 27, 3713-3724, doi:10.5194/angeo-273713-2009, 2009b.

Paulsen, D. E., Huffman, R. E., and Larrabee, J. C: Improved photoionization rates of $\mathrm{O}_{2}\left({ }^{1} \Delta \mathrm{g}\right)$., Radio Sci., 7, 51-55, 1972.

Picone, J. M., Hedin, A. E., Drob, D. P., and Aikin, A. C.: NRLMSISE-00 empirical model of the atmosphere: Statistical comparisons and scientific issues, J. Geophys. Res., 107, 1468, doi:10.1029/2002JA009430, 2002.

Polyakov, A. V., Timofeyev, Y. M., Ionov, D. V., Virolainen, Y. A., Steele, H. M., and Newchuch, M. J.: Retrieval of ozone and nitrogen dioxide concentrations from Stratospheric Aerosol and Gas Experiment III (SAGE III) measurements using a new algorithm, J. Geophys. Res., 110, D06303, doi:10.1029/2004JD005060, 2005.

Porter, H. S., Jackman, C. H., and Green, A. E. S.: Efficiencies for production of atomic nitrogen and oxygen by relativistic proton impact in air, J. Chem. Phys., 65, 154-165, 1976.

Rees, M. H.: Physics and chemistry of the upper atmosphere, Cambridge University Press, Cambridge, UK, 1989.

Rodrigo, R., Lopez-Moreno, J., Lopez-Puertas, M., Moreno, F., and Molina, A.: Neutral atmospheric composition between 60 and $220 \mathrm{~km}$ : A theoretical model for mid-latitudes, Planet. Space Sci., 34, 723-743, 1986.

Sander, S. P., Golden, D. M., Kurylo, M. J., Moortgat, G. K., Ravishankara, A. R., Kolb, C. E., Molina, M. J., and Finlayson-Pitts,
B. J.: Chemical kinetics and photochemical data for use in atmospheric studies, Evaluation Number 14, JPL Publication 0225, Jet Propulsion Laboratory, California Institute of Technology, Pasadena, USA, 2003.

Sandor, B. J., Clancy, R. T., Rusch, D. W., Randal, C. E., Eckman, R. S., Siskind, S., and Muchleman, D. O.: Microwave observations and modeling of $\mathrm{O}_{2}\left({ }^{1} \Delta_{2}\right)$ and $\mathrm{O}_{3}$ diurnal variation in the mesosphere, J. Geophys. Res., 102, 9013-9028, 1997.

Shepherd, M. G., Reid, B., Zhang, S., Solheim, B., Shepherd, G. G., Wickwar, V. B., and Herron, J. P.: Retrieval and validation of mesospheric temperatures from Wind Imaging Interferometer observation, J. Geophys. Res., 106, 24813-24829, 2001.

Shimazaki, T. and Laird, A.: A model calculation of the diurnal variation in minor neutral constituents in the mesosphere and lower thermosphere including transport effects, J. Geophys. Res., 75, 3221-3235, 1970.

Shimazaki, T. and Laird, A.: Seasonal effect on distributions of minor constituents in the mesosphere and lower thermosphere, Radio Sci., 1, 23-43, 1972.

Siskind, D. E. and Rusch, D. W.: Nitric oxide in the middle to upper thermosphere, J. Geophys. Res., 97, 3209-3217, 1992.

Siskind, D. E. and Russel, J. M.: Coupling between middle and upper atmospheric NO: constrains from HALOE observations, J. Geophys. Res. Lett., 23, 137-140, 1996.

Siskind, D. E., Bacmeister, J. T., Summers, M. E., and Russel, J. M.: Two-dimensional model calculations of nitric oxide transport in the middle atmosphere and comparison with Halogen Occultation Experiment data, J. Geophys. Res., 102, 3527-3545, 1997.

Siskind, D. E., Barth, C. A., and Russel, J. M.: A climatology of nitric oxide in the mesosphere and thermosphere, Adv. Space Res., 21, 1353-1362, 1998.

Smirnova, N. V., Ogloblina, O. F., and Vlaskov, V. A.: Modelling of the lower ionosphere, Pageoph., 127, 353-379, 1988.

Smirnova, N. V., Ogloblina, O. F., Vlaskov,, V. A., and Semyachkina, T. N.: Catalogue of the electron number density of the D region. Preprint PGI - 90 -04 - 72, Academy of Sciences USSR, 1990 (in Russian).

Smith, F. L. and Smith, C.: Numerical evaluation of Chapman's grazing incidence integral, J. Geophys. Res., 77, 3592-3597, 1972.

Solomon, S., Reid, G. C., Roble, R. G., and Crutzen, P. J.: Photochemical coupling between the thermosphere and the lower atmosphere, 2. D region ion chemistry and the winter anomaly, J. Geophys. Res., 87, 7221-7227, 1982.

States, R. J. and Gardner, C. S.: Influence of the diurnal tide and thermospheric heat sources on the formation of mesospheric temperature inversion layers, Geophys. Res. Lett., 25, 1483-1486, 1998.

Swider, W.: Ion production in the D-region, Solar Terrestrial Predictions Proceedings, Working Group Rep. and Rev., Boulder V.2, 599-616, 1979.

Theon, J. S., Nordberg, W., Katchen, L. B., and Horvath, J. J.: Some observations of the thermal behavior of the mesosphere, J. Atmos. Sci., 24, 428-438, 1967.

Thomas, L. and Bowman, M. R.: The diurnal variations of hydrogen and oxygen constituents in the mesosphere and lower thermosphere, J. Atmos. Terr. Phys., 34, 1843-1858, 1972.

Torr, M. R., Torr, D. G., Ong, R. A., and Hinteregger, H. E.: Ionization frequencies for major thermospheric constituents as a func- 
tion of solar cycle 21, Geophys. Res. Lett., 6, 771-774, 1979.

Turco, R. P. and Sechrist, C. F.: An investigation of the ionospheric D-region at sunrise. 1. Time variations of ozone, metastable molecular oxygen and atomic oxygen, Radio Sci., 7, 703-716, 1972.

Verronen, P. T., Turunen, E., Ulich, Th., and Kyrölä, E.: Modelling the effects of the October 1989 solar proton event on mesospheric odd nitrogen using a detailed ion and neutral chemistry model, Ann. Geophys., 20, 1967-1976, doi:10.5194/angeo-201967-2002, 2002.
Yu, J., States, R., Franke, S. J., Gardner, C. S., and Hagan, M.: Observations of tidal temperature and wind perturbations in the mesopause region above Urbana, IL $\left(40^{\circ} \mathrm{N}, 88^{\circ} \mathrm{W}\right)$. Geophys. Res. Lett., 24, 1207-1210, 1997.

Zadorozhny, A. M.: Diffusion-photochemical model of minor neutral constituents in the lower ionosphere, edited by: Academy of Science of USSR, Novosibirsk, 1982 (in Russian).

Zommerfields, W. C., Kinzni, K. F., Summers, M. E., Bevilacqua, R. M., Strobel, D. F., Allen, M., and Sawchuck, W. J.: Diurnal variations of mesospheric ozone obtained by ground-based microwave radiometry, J. Geophys. Res., 94, 12819-12832, 1989. 